\title{
The Relationship between Occlusion and TMD
}

\author{
Frank E. Cordray \\ Department of Orthodontics, Ohio State University, Columbus, OH, USA \\ Email: cordrayortho@aol.com
}

How to cite this paper: Cordray, F.E. (2017) The Relationship between Occlusion and TMD. Open Journal of Stomatology, 7, 35-80.

http://dx.doi.org/10.4236/ojst.2017.71003

Received: November 24, 2016

Accepted: January 7, 2017

Published: January 10, 2017

Copyright $\odot 2017$ by author and Scientific Research Publishing Inc. This work is licensed under the Creative Commons Attribution International License (CC BY 4.0).

http://creativecommons.org/licenses/by/4.0/

\begin{abstract}
The purpose of this paper is to conduct an extensive review of the literature on the relationship between occlusion and occlusal factors and TM dysfunction. This paper attempts to explore why the link between occlusal factors, which have historically been implicated in producing TMD, and dysfunction has not been clearly evident from the dental literature.

\section{Keywords}

Dental Arch Displacement (DAD), Condylar Displacement (CD), Seated Condylar Position (SCP), Maximum Intercuspation (MIC), Intercuspal Position (ICP), Musculo-Skeletal Dysfunction, Temporo-Mandibular Dysfunction (TMD), Common Muscle Contraction Headache (CMCH)
\end{abstract}

\section{Introduction}

The role of occlusion as an etiologic factor in temporomandibular dysfunction (TMD) is a controversial subject. It sometimes elicits strong emotions and is often discussed at a highly empirical level. Many dentists believe that occlusal discrepancies are an important etiologic factor in TMD, and their belief is reinforced by successful results following occlusal treatment. However, other clinicians claim equal success following the use of nonocclusal treatments. This being the case, it would be unwise to base any theory on the etiology of dysfunction solely on subjective assessments of pain relief [1].

Studies on the role of occlusal factors in TMD fall broadly into four categories. They may be 1) experimental, 2) electromyographic, 3) epidemiologic, or 4) clinical. The evidence contained in these studies is often conflicting, and some of the studies have serious shortcomings. For example, had occlusal factors not been dismissed as unimportant in some studies, the results could have been interpreted differently [1].

The signs of TMD include muscle and joint tenderness, joint sounds, limitation and incoordination of mandibular movement, parafunction, occlusal wear, 
attrition, and headache. It is now generally accepted that headache should be included as an additional sign, [2] especially since common muscle contraction headaches $(\mathrm{CMCH})$ have been reported to account for up to $90 \%$ of all headache pain [3]. Epidemiologic and clinical studies indicate that some signs of dysfunction may be present without producing pain. However, pain is the main complaint and the principle reason why patients seek treatment [1].

The etiology of pain and dysfunction remains unclear. Some authors believe that there is a single etiologic factor, either occlusal [4] [5] [6] or psychological [7]. Others reason that because there is no consistent pattern of presentation, the etiology is probably multifactorial [8]. Nonetheless, there is general agreement that external trauma is often a predisposing factor [1] [8] [9] [10].

The primary focus in the study of TMD has traditionally been neuromuscular (extracapsular) [8]. However, the pathologic processes occurring within the joint (intracapsular) have also become a significant area of focus in recent years, especially with the use of improved imaging techniques. Intracapsular and extracapsular dysfunctions are often superimposed and pose a considerable diagnostic challenge in determining to what extent each condition is dependent upon the other. Clinicians treating these problems are well aware that extracapsular (muscular) problems have a significantly better prognosis for resolution than intracapsular (structural) problems.

\subsection{Experimental Studies}

Table 1 shows the incidence of TMD as determined by muscular and/or temporomandibular joint (TMJ) pain one week after placement of various interferences in small samples of subjects [1] [11] [12] [13] [14] [15]. Surprisingly, the incidence of dysfunction varied from high (7/8) to low (0/6) in these five studies. Two glaring weaknesses of these studies are the extremely small sample sizes and the short periods over which symptoms were monitored-long-term follow-ups would have been more useful. The outcome of this type of experiment is most likely determined by the subject's neuromuscular adaptive capacity, or in other words, the subject's ability to "absorb" an interference without producing significant degrees of muscular incoordination, hyperactivity, or parafunction [1]. This range of individual accommodation determines the likelihood of pathologic sequelae.

\subsection{Electromyographic Studies}

Electromyography measures the character and intensity of electrical activity associated with muscular contraction. Studies comparing dysfunctional and nondysfunctional subjects found that most TMD patients showed increased and uncoordinated electromyographic (EMG) activity of the masticatory muscles [1] [5] [16]. Studies also found that in many cases the EMG silent period (the temporary pause in ongoing EMG activity of jaw-closing muscles during maximal clench) is also longer in TMD, which implies a possible neuromuscular difference between TMD and non-TMD subjects [1] [17] [18]. The exact cause of the 
Table 1. Experimental studies in which various occlusal interferences were incorporated [1]. The incidence of dysfunction after 7 days is reported in the last column.

\begin{tabular}{cccc}
\hline & $\begin{array}{c}\text { Investigator (Yr) } \\
\mathrm{n}=\end{array}$ & Posterior interference & $\begin{array}{c}\text { Subjects with dysfunction } \\
\text { after 7 days }\end{array}$ \\
\hline Randow '76 & 8 & $0.5 \mathrm{~mm}$ high inlay & $7 / 8$ \\
Riise '82 & 11 & $0.5 \mathrm{~mm}$ high amalgam & $4 / 11$ \\
Plata '82 & 6 & Lateral deflective contact & $0 / 6$ \\
Rugh '84 & 10 & $\begin{array}{c}\text { Crown with 0.5 - 1 mm } \\
\text { shift ant + lat from CR }\end{array}$ & $4 / 10$ \\
Magnusson '84 & 12 & $\begin{array}{c}\text { Bilateral nonworking composites } \\
\text { Control: simulated }\end{array}$ & $7 / 12$ \\
& 12 & & $3 / 12$ \\
\hline
\end{tabular}

abnormal EMG activity is unclear. However, parafunction (clenching and bruxism) have been implicated [1] [19] [20].

Finally, studies have found that bruxists with TMD showed a decrease in both diurnal EMG hyperactivity and incoordination following occlusal adjustment [1] [21] [22]. Patients who developed TMD following restorative treatment also showed a decrease in diurnal EMG activity after the occlusal discrepancies were removed from their restorations after occlusal adjustment [1] [23].

\subsection{Epidemiologic Studies}

Several studies have investigated the prevalence of TMD in the general population. Rugh and Solberg have reviewed these studies [24]; their findings may be summarized as follows:

The prevalence of symptoms ( $12 \%$ to $59 \%$ ) and signs ( $28 \%$ to $86 \%)$ was generally high. However, most cases were subclinical, and it was estimated that no more than $5 \%$ required treatment. Interestingly, the female-male ratio of dysfunctional subjects was 1:1 in these studies, whereas the ratio of TMD patients actively seeking treatment had a female-male ratio of 3:1. Peak age on presentation was 20 to 30 years [25] (historically, dysfunction has been implied to occur in adults much more frequently than in younger subjects). The ability of a subject to adapt to occlusal discrepancies may be influenced by psychic stress [26] [27] [28]. A number of occlusal factors have been linked with TMD [1]. These include loss of vertical dimension [4], number of contacting teeth [29], orthodontic malocclusion (specifically, crossbite, anterior open bite, and deep bite) [30], occlusal interferences, and deflective contacts [21] [22] [26] [31] [32] [33] [34]. However, the link between occlusal factors, which have been implicated in producing TMD, and dysfunction is not always evident from the literature [1].

There has been much speculation on the way in which occlusal factors may produce dysfunction. It can be understood that posterior tooth loss, particularly in the presence of parafunction, can predispose to overloading the TMJ [4]. The mode of action of occlusal interferences and deflective contacts is more difficult to determine. However, there are two principle theories. The first theory is that 
occlusal factors induce the subject to parafunction [26]. The second theory is that functional movements (mastication, swallowing, mandibular posturing) are adversely affected when the subject subconsciously avoids the aberrant tooth contact [35]. This is known as aberrant function [1]. Both theories acknowledge that psychic stress may combine with an unfavorable occlusion to produce dysfunction. Parafunction and aberrant function may produce muscular hyperactivity [21] [22] and incoordination [36]. Balancing interferences may act as pivots that produce adverse leverages, thus overloading the TMJ components in compression or tension [1] [37].

\subsection{Clinical Studies}

Clinical studies have historically been the method of choice for studying occlusion and the effectiveness of occlusal alteration on the reduction of TMD signs and symptoms.

\subsubsection{Occlusal Therapy}

The next point to consider is the effectiveness of occlusal therapy in treating TMD. Over the last five decades, occlusal therapy has included reconstruction (often at an increased vertical dimension [38]) and occlusal adjustment (reshaping heavy intercuspal contacts [39] and deflective interferences) [26] to enhance functional relationships. The response of TMD patients to occlusal therapy has been assessed both subjectively by patients' reports of pain remission [40] [41] and objectively, utilizing EMG data [17], the Helkimo dysfunction index, [42] pantographic tracings [36] [43] [44] [45] [46] condylar radiography [47], gnathosonic recording [39], and three-dimensional condylar position (graphic) registrations [33] [34].

Small yet significant interferences may be clinically difficult to detect and the characteristics of pantographic tracings have been shown to be useful in revealing their existence [1]. The identification of the interference and its removal have been shown to result in the establishment of normal border movements [43]. Clayton introduced a method of detecting and quantifying mandibular incoordination using the pantograph; the degree of divergence of three consecutive tracings forms the basis for his pantographic reproducibility index (PRI). Pantographic tracings quantitated by the PRI can be used to detect the existence of uncoordinated mandibular movements, a symptom of TMD [44]. When the masticatory muscles are incoordinated, mandibular border movements become nonreproducible [45]. Splint therapy has been shown to produce a fall in this index and an immediate rise to dysfunctional levels upon splint removal [48]. The findings of these PRI studies support the epidemiologic studies cited earlier, which found that signs associated with dysfunction can exist without pain [1].

Ramfjord [21] [22] used electromyography to evaluate the effects of occlusal adjustment on a population of 35 bruxists with symptoms of TMD. Excessive EMG activity was normalized after adjustment, and all symptoms were alleviated. This study is often cited in support of occlusal adjustment as an effective 
mode of therapy. However the study has several methodological problems: no controls were used; long-term follow-up was not reported, and the study has not been duplicated.

Magnusson and Carlsson utilized the Helkimo dysfunction index to monitor the effect of further occlusal adjustment in patients who had residual signs and symptoms of TMD 2 to 5 years after initial occlusal adjustment. The treatment was found to be effective in removing the preadjustment signs and symptoms [1] [49].

Thus occlusal adjustment studies suggest that occlusal adjustment can reduce the clinical signs of TMD. However, the problem with studies of this type are that they lack controls, that treatment is not randomly allocated, and the occlusal adjustment method is sometimes questionable [1].

\subsubsection{Splint Therapy}

Early studies [5] [50] demonstrated that the provision of a full-coverage stabilizing splint adjusted to the seated condylar position (SCP) (synonymous and interchangeable terms are used here to describe two key reference positions; SCP/CR Seated Condylar Position/Centric Relation and MIC/CO for Maximum Intercuspation/Centric Occlusion) produces an immediate drop in EMG, which returns to its previous level upon splint removal. The anterior guidance provided by the splint has been shown to be significant [51]. In his comprehensive review of splint designs, Clark concluded that there is only sufficient evidence to support the use of the stabilizing splint adjusted to the SCP [52] [53]. Wahlund, in a prospective randomized clinical trial, showed that stabilization splints are highly effective for treatment of TMD, especially in adolescents [54]. In addition, a 23-year clinical study has shown that the stabilizing splint is more effective long term than an anterior-repositioning splint [55] and is less likely to lead to difficult orthodontic and restorative problems caused by unwanted tooth movement [1] [10]. Some authors advise an initial period of stabilization splint wear for therapeutic or diagnostic purposes [46] [48]. Therapeutic goals are to alleviate the symptoms of TMD and to test the patient's response to an altered occlusal scheme. The diagnostic goal is to reveal occlusal interferences and maxillomandibular relationships previously hidden by guarding of the neuromuscular system. Thus splint therapy is used to locate the seated condylar position, to test the stability of the joints, and to determine if changing the patient's existing occlusal scheme may be of benefit.

\section{Three-Dimensional Determination of Condylar Position}

The seated condylar position (SCP) or Centric Relation (CR) is anatomically determined; thus it is repeatable and reproducible [26] [56] [57]. It is defined as the relationship of the mandible to the maxilla when the condyles are seated against the thinnest avascular portion of the articular disc in their most superoanterior position in the glenoid fossae and are centered transversely, regardless of tooth contact [57] [58]. Okeson [57] describes this as the most orthopedically and 
musculoskeletally stable position of the mandible, while Sicher [59], Hylander [60], and Gibbs and Lundeen [61] consider this position to be the essence of optimal TMJ form and function. It is considered to be the most reliable and reproducible reference point for accurately recording the relationship of the mandible to the maxilla [56] [57] [62]-[67]. Therefore, determination of the SCP/CR is a prerequisite for analyses of dental inter-arch, condylar position, and skeletal (maxillomandibular) relationships.

Maximum intercuspation or centric occlusion (MIC/CO) is defined as the most closed position that the mandible can assume, determined by full intercuspation of opposing teeth, regardless of condylar position [58]. The SCP/CR defines a condylar-determined position of the mandible, whereas MIC/CO defines a tooth-determined position. It is generally agreed that a difference exists between the three-dimensional dental inter-arch relationships in the SCP/CR and $\mathrm{MIC/CO}$ [68] [69] [70] [71] [72]. It is also generally agreed that a difference exists between the three-dimensional condylar position in MIC/CO (the occlusiondictated condylar position) and in the SCP/CR (the three-dimensional condyle position when the condyles are seated) [33] [34] [66] [69] [70] [71] [73]-[84]. In the naturally occurring dentition, the SCP/CR does not usually coincide with the position the mandible assumes when the teeth are in MIC/CO [26] [33] [34] [35] [36] [48] [51] [52] [53] [56] [57] [58] [62]-[84]. This positional difference is known as condylar displacement [34] [63] [64] [72]-[79] [84].

Howat et al. [56] state that the discrepancy between the seated and unseated condylar position should be identified and eliminated when the operator reorganizes the occlusion. The occlusion is reorganized when the operator is restoring posterior occlusal stability by occlusal adjustment or tooth restoration; is treating mandibular dysfunction; is treating with orthodontics; or is positioning the condyle during orthognathic surgery. The occlusion is also reorganized prior to multiunit restorations or complete denture prosthetics. Thus, treatment success in each of these areas is completely dependent upon the operator's ability to attain a comfortable, stable, repeatable seated condylar position as a reference point.

Various clinical methods have been proposed to determine condylar position as it relates to the dentition. One popular method is a chairside assessment through intraoral visual estimation, using mandibular manipulation to attempt to seat the condyles [49]. However, attempts to assess the dental arch displacement (DAD) in the general population through intraoral visual estimation are not reliable, because the muscles of mastication and neuromuscular reflexes protect the teeth by overriding the guidance of the joint [33] [34] [56] [62] [69] [70] [71] [84]-[92]. Another popular method is to estimate the degree of condylar displacement by measuring the hit-and-slide (DAD) at the occlusal level [93]. However, studies have shown that observation of a slide or shift at the level of the occlusion (DAD) may not accurately represent the three-dimensional change in position of the condylar axis [33] [34] [63] [64] [73]-[79] [81] [82] [83] [84].

The American Dental Association [94] and the American Academy of Cra- 
niomandibular Disorders [95] have concluded that radiographs are contraindicated to assess condylar position for diagnostic purposes [96]-[112]. Radiographs include panoramic and transcranial radiographs, lateral cephalograms, arthrograms, and corrected tomography. These are two-dimensional images and are therefore inadequate to assess condylar position, which exists in three planes of space. As with all radiography, there is a certain percentage of distortion inherent in the production of a radiographic image. A problem with tomography is the variation in soft tissue thickness within the joint, which creates joint space that is not three-dimensionally uniform. Hatcher [113] has shown that the evaluation of condylar position is very sensitive to the depth of cut, and that head position is critical. Thus, a large variation in condylar position, as seen tomographically, has been found in normal asymptomatic subjects [33] [75] [99] [100] [101] [112] [113]. Girardot [33] observed that condlar position measurements obtained with the MPI were different from those obtained with oriented tomograms, even though the same condyles were being measured. He concluded that MPI instrumentation is a more reliable method of measuring changes in condylar position than tomographic radiographs and questioned the validity of using tomograms as a means of measuring changes in condylar position. Arthrography and arthroscopy are expensive and invasive procedures that often yield information of questionable value, while MRIs [75] and CT scans are expensive, not readily available, and do not record condylar position three-dimensionally. Contemporary imaging methods, such as CBCT scans, have improved accuracy and are three-dimensional anatomic recordings, but are rarely taken with the condyles seated, most often being taken with the mandible in the MIC/CO position due to convenience.

The use of study models articulator mounted in the SCP/CR in conjunction with condylar position instrumentation is another method of assessing threedimensionally both the dental inter-arch relationship and position of the condyles. The magnitude and direction of any discrepancy between the SCP/CR and $\mathrm{MIC/CO}$ is determined with condylar position instrumentation, designed to record, measure, quantify, and compare the positional changes of the condylar axis between the SCP/CR and MIC/CO in all three spatial planes. Specifically, this means that this instrumentation is capable of recording $\mathrm{mm}$. measurements of condylar position in the horizontal (AP), vertical (SI), and transverse (ML) planes. The accuracy, reproducibility, and reliability of condylar position instrumentation have been confirmed [33] [34] [63] [64] [73]-[79] [81] [82] [83] [84] [114] [115] [116] [117]. A number of articulator systems incorporate this type of condylar position instrumentation. They include the Cranio-Mandibular Positioner (CMP) (formerly Veri-check), by Denar Corporation, Anaheim, California, the SAM Mandibular Position Indicator (MPI), by Great Lakes Orthodontics, Ltd., Tonawanda, New York, the Modified Buhnergraph, by Whip-Mix Corportion, Louisville, Kentucky, the Condylar Position Indicator (CPI), by Panadent Corporation, Grand Terrace, California, and the Measure of Condylar Displacement (MCD), by AD2 (Advanced Dental Designs), Riverside, Califor- 
nia.

Condylar graph measurement using condylar position instrumentation has many advantages. It is simple and easy to perform; it is widely available; it is inexpensive and noninvasive; it is suitable for screening large numbers of patients; and it is highly accurate. It is the most accurate method for determining condylar position in all three planes of space (to within $0.2 \mathrm{~mm}$ horizontal and vertical and $0.1 \mathrm{~mm}$ transverse) [33] [34] [63] [64] [73]-[79] [81] [82] [83] [84] [114] [115] [116] [117]. The seated condylar position is a three-dimensional entity that is most accurately assessed with a three-dimensional measuring device, such as those listed above.

Therefore, a definitive three-dimensional description of occlusion includes not only an assessment of dental casts articulated accurately in the SCP/CR, but also an assessment of condylar position resulting from intercuspation of the teeth. A definitive description of occlusion must answer the following questions. Does the maximum intercuspation of teeth allow the condyles to remain seated? Is the occlusion-dictated condylar position (the position of the condyle in MIC/ $\mathrm{CO})$ coincident with the SCP/CR? Or are the condyles displaced as the teeth are brought into MIC/CO? If the condyles are displaced, what is the magnitude and direction of this displacement in three planes? What is the normal range for condylar displacement in an asymptomatic population? Is it different in a symptommatic population? It is of paramount importance to answer these questions when attempting to determine whether occlusion is associated with the production of the signs and symptoms of TMD.

\section{Problems with Researching Occlusion}

It is apparent that further work needs to be done to clarify the confusing situation that exists relating TMD to deflective dental contacts and interferences and thus to condylar displacement. To address this problem, it is necessary to determine why the link between TMD dysfunction and occlusal factors which have been implicated in producing TMD dysfunction has not been sufficiently evident in the literature [1]. The fact that a number of previous studies [100] [101] [112] [118]-[129] have failed to find a strong link between occlusal factors, condylar position, and TMD does not prove there is no such link. The most recent literature denying the existence of a link has shown only that 1) there is no correlation in random samples between the location of the condyles on a radiograph and TM symptoms [96]-[113]; or 2) that there is only a weak association between occlusal factors in MIC/CO and TM symptoms [1].

For example, occlusal characteristics such as overbite and overjet have been shown to be poor indicators of condylar position [33] [34] [58] [63] [73] [81] [82] [83] [84] [113] [114] [115] [116] [117]. Recent studies have also shown that the frequency, magnitude, and direction of the displacement between the SCP/ $\mathrm{CR}$ and $\mathrm{MIC} / \mathrm{CO}$ at the level of the condyles cannot be predicted by age, gender, Angle's classification ANB angle, or mandibular plane angle [76] [78]. Conversely, many studies have shown a positive correlation between occlusal factors, 
condylar position, and TMD [26] [31] [33] [34] [35] [47] [49] [103] [130]-[158]. Why does a dichotomy exist in the results and conclusions of these two sets of studies? Methodology is one area that can be implicated.

\subsection{Methodologic Inaccuracies}

The overwhelming majority of studies researching a possible link between occlusal factors, condylar position, and TMD are methodologically flawed in one or more of the following respects. First, researchers have not adequately addressed the influence of the neuromusculature on condylar position and the resulting dental inter-arch relationship. Researchers have not routinely used deprogramming to achieve neuromuscular release before conducting occlusal and condylar position evaluations. Second, condylar position and condylar displacement have not been isolated as a specific etiologic factor in the possible production of TM signs, symptoms, and dysfunction. Third, condylar position and condylar displacement (CD) have not been accurately evaluated in three dimensions. Fourth, instrumentation is required to assess and compare the threedimensional dental arch displacement (DAD) and condylar displacement (CD) between MIC/CO and the SCP/CR. Fifth the use of instrumentation is technique sensitive. Sixth, and finally, the study sample may simply be too small to render the conclusions clinically valid.

These methodologic inaccuracies blur the distinction between the SCP/CR and MIC/CO both at the level of the occlusion and at the level of the condyles. For example, many studies have attempted to evaluate condylar displacement (CD) without the use of instrumentation through measurement of the apparent hit-and-slide (DAD) at the occlusal level by intraoral visual estimation and chairside mandibular manipulation of a nondeprogrammed symptomatic subject, or through assessment of study models hand-articulated in MIC/CO. Others have attempted to evaluate condylar displacement on a nondeprogrammed symptomatic subject radiographically. Add to this the fact that accurately registering the SCP/CR is technique sensitive to the point that many dental practitioners and researchers find it impossible and it becomes clearer why only a weak association has been found between occlusal factors in MIC/CO and TMD symptoms. It is also apparent that very few studies that attempt to evaluate the difference between the SCP/CR and MIC/CO in asymptomatic and symptomatic subjects actually register the SCP/CR accurately, for this requires deprogramming prior to the registration of the SCP/CR and the use of instrumentation by a researcher versed in these techniques to measure the dental arch displacement (DAD) and condylar displacement (CD).

\subsection{Influence of the Neuromusculature}

To study the dental inter-arch and condyle positional changes between MIC/CO and the SCP/CR, it is important to use a method that reduces or eliminates the influence of the occlusion on the musculature. Only then can the condyles be accurately seated. A number of studies have shown that the neuromusculature 
positions the mandible to achieve maximum intercuspation regardless of the position of the condyles [21] [33] [45] [48] [50] [69] [71] [79] [84] [86] [91]. Engrams (as a result of muscle splinting and activation of the premature avoidance system) develop due to repetitive closure in a deviated position. This causes the proprioceptive neuromuscular system to memorize muscle activity and thus become patterned to the deviated closure, which may prevent complete condylar seating whten registering the SCP/CR [57] [79] [85] The resultant muscle function can be so dominant that the clinician will mistake the acquired mandibular position (the occlusion-dictated condylar position) for the seated condylar position. Thus clinical mandibular manipulation is an unreliable means of determining the seated condylar position. This finding is consistent with Calagna's statement that "there is no known scientific method available to determine which patients require nerumuscular conditioning" [69].

Neuromuscular deprogramming is the key to reproducibility [21] [33] [45] [48] [50] [56] [57] [62] [64] [68] [69] [70] [71] [79] [84]-[92]. A tangible result of more complete condylar seating is that the clinician is provided with a more accurate representation of both the three-dimensional dental inter-arch and condylar position spatial relationships. Deprogramming allows location of the seated condylar position and resultant occlusal analysis that correlates condylar position with tooth contacts. Studies have shown that the neuromusculature positions the mandible so that the teeth fit into MIC/CO irrespective of condylar position [33] [34] [56] [62] [63] [64] [69] [70] [71] [73]-[79] [84]-[92]. Thus it can be difficult to identify deflective dental contacts and to register the SCP/CR in dysfunctional subjects [1].

If dysfunctional subjects have not been symptomatically resolved and neuromuscularly deprogrammed on a stabilizaiton splint prior to registration of the $\mathrm{SCP} / \mathrm{CR}$, then the occlusal and condylar position evaluations were performed while the subjects were still dysfunctional [1]. Failure to register the SCP/CR accurately results in studies in which all samples (both control and experimental) are similar with regard to condylar position. Therefore only occlusal factors in $\mathrm{MIC/CO}$ are being measured in each sample. The result is that only minimal discrepancies in condylar position are observed between $\mathrm{MIC} / \mathrm{CO}$ and the assumed SCP/CR.

\subsection{The Need for Instrumentation}

Few studies have examined occlusion-dictated condylar position and condylar displacement with condylar position instrumentation. Instead, previous researchers have attempted to study occlusion intraorally, with study models hand articulated in $\mathrm{MIC} / \mathrm{CO}$, with radiographs, or with a magnetic resonance imaging (MRI) or computed tomography (CT) scan. One possible reason for this is that the methods for registering the SCP/CR and measuring condylar displacement are highly technique sensitive. Studies conducted by unskilled or inexperienced clinicians or researchers result in erroneous, invalid, or flawed conclusions [1]. A second possible reason is that the use of instrumentation can be labor inten- 
sive, making it difficult to secure a sample size sufficient to prove a strong statistical significance or to provide accurate conclusions.

\section{Why the Epidemiologic Evidence Implicating Occlusion as a Causative Factor in TMD Is Weak}

No clearly defined link has been determined from the epidemiological literature relating occlusal factors or condylar position and TMD. How can this be? There may, in truth, be no link, because the dysfunction may arise as a result of other factors. However, other reasons must be considered. The literature relating occlusal factors and condylar position to TMD must be assessed in the context of the clinical problems that affect this possible relationship [1]. These problems may be summarized as follows:

1) TMD is multifactorial [1] and the etiology and extent of TMD are difficult to diagnose precisely [1].

2) The occlusal and condylar position evaluations that form the basis of these studies may have been inadequate. For example, dental inter-arch relationships may have been estimated visually. Study models may have been hand articulated in MIC/CO. The condylar registration technique may have been improperly conducted (e.g. no dental instrumentation or radiographic evaluation (MRI, CT scan, $\mathrm{CBCT}$ ) conducted in $\mathrm{MIC} / \mathrm{CO}$ ).

3) The identification and full extent of deflective occlusal contacts in dysfunctional subjects may be hidden by guarding of the neuromusculature. For example, it is difficult to identify deflective dental contacts in subjects with TMD [1]. Numerous studies [50] [51] [57] [69] [70] [71] [79] [84] [86] [93] [159] have shown that properly conducted splint therapy or neuromuscular deprogramming reveals previously undetected occlusal contacts as a result of masticatory muscle relaxation and subsequent mandibular repositioning. This implies that in dysfunctional subjects, effective treatment must be implemented before precise occlusal analysis is undertaken. Many studies have ignored this consideration. Some of these studies [160] [161] [162] [163] report no relationship between deflective dental contacts and DAD between MIC/CO and the SCP/CR, but in these studies, the subjects' proprioceptive response to the occlusion was not eliminated. Thus, the occlusal evaluations were conducted while the subjects were still dysfunctional. And even if mandibular posturing can be overcome, an appropriate method must be used to assess deflective dental contacts and occlusal interferences. Some studies [164], have used study casts mounted on non-arcon semiadjustable articulators [164]. This method of assessment is inappropriate because the posterior determinants of occlusionare not sufficiently accurate to identify working and balancing interferences reliably [1].

4) Neuromuscular Adaptive Capacity. Occlusal factors may cause little or no dysfunction because they lie within the subject's neuromuscular adaptive capacity [1] [26] [56]. However, the same factors may exceed the adaptive capacity of a subject susceptible to TMD, causing muscular hyperactivity and incoordination [1]. The type and severity of deflective dental contact and occlusal interfe- 
rence may be less important than the way the dysfunctional subject reacts to it. Thus the differences in occlusion between dysfunctional and asymptomatic subjects may be minimal [1]. However, the transverse (medio-lateral) condylar displacement, commonly present with dental cross bite, has been implicated as a possible etiologic factor in TMD [34] [62] [73] [74] [76] [83] [85] [87] [117] [144] [151] [156].

5) The neuromuscular adaptive capacity may be lowered by stress and emotional problems [1].

It is probably for these reasons that the epidemiologic evidence to implicate occlusal factors in dysfunction is weak. Nevertheless, despite their shortcomings, experimental, electromyographic, and clinical studies have demonstrated the effect of deflective occlusal contacts on muscle activity. And there is no doubt that experimental and iatrogenic interferences in susceptible individuals will produce excessive and incoordinated muscle activity. Similarly, the removal of interferences in TMD subjects can reduce and coordinate muscle activity. Occlusal therapy has been shown in the literature to have both subjective and objective effects on dysfunction. Most other therapies have been shown to improve pain only [1].

\section{Recommendations for Occlusion Research}

While researchers and practitioners accept that the etiology of TMD is multifactorial, and the etiology and extent of TMD are difficult to diagnose precisely, this author would like to propose the following research guidelines in an attempt to improve upon the methodologic problems described above [1] [161].

\subsection{Sample Selection Requirements}

Pain in the head, neck, and TMJ region may involve many etiologic factors and the specific source of pain is often misdiagnosed by both medical and dental clinicians and researchers. The term "headache" can mean many things to both the patient and the clinician, either medical or dental. For example, the most prevalent type of headache is the common muscle contraction headache ( $\mathrm{CMCH})$. In addition, medical practitioners rarely consider a structural or functional impairment, and the majority treat these problems with nonspecific pain medications only. This leads to the following recommendations:

1) Differential diagnosis of pain is essential in sample selection.

2) Simple, universally accepted systems of assessing the location and degree of dysfunction need to be developed and applied to TMD research protocol. By definition, TM dysfunction is limited to muscular and structural impairment.

3) Samples must be large enough to prove statistical significance and render the conclusions clinically valid.

\subsection{Methodologic Requirements}

It is important to eliminate the influence of the neuromusculature on condylar position and the resulting three-dimensional dental inter-arch relationships to 
accurately register the SCP/CR as a reference, and to determine the resultant dental inter-arch relationships and occlusion-dictated condylar position in three spatial planes. The identification and full extent of deflective occlusal contacts and condylar displacement may be hidden by guarding of the neuromusculature. Thus, subjects (both symptomatic and asymptomatic) should be deprogrammed prior to occlusal and condylar position evaluations. Stabilization splint therapy is required to resolve symptoms of symptomatic and dysfunctional subjects. Deprogramming is required for both asymptomatic and symptomatic subjects prior to the registration of the SCP/CR, to eliminate the subject's neuromuscular response to the habitual occlusion.

Condylar displacement should be isolated and considered as a specific etiologic factor in the production of TM signs, symptoms, and dysfunction. The occlusal and condylar position evaluations should be accurate and appropriate. Instrumentation is required to assess and compare the three-dimensional dental arch displacement (DAD) and condylar displacement (CD) between MIC/CO and the SCP/CR. Dental instrumentation (an articulator mounting in the SCP/ $\mathrm{CR}$ and condylar graph measurements) has proven to be valid, reproducible, accessible, cost-effective, noninvasive, and highly accurate [33] [34] [63] [64] [73]-[79] [81] [82] [83] [84] [114] [115] [116] [117]. Inadequate methodology includes intraoral visual estimation, study models hand articulated in $\mathrm{MIC} / \mathrm{CO}$, improper registration techniques, no utilization of dental instrumentation, radiographic evaluation, and scans not conducted in the SCP/CR (MRI, CT, and CBCT).

Utilizing these more sophisticated techniques researchers need to compare DAD and CD to joint imaging techniques [26] [33] in asymptomatic and symptomatic subjects, and before and after occlusal treatment. For example, if it is accepted that the etiology of TMD is multifactorial and the individual's adaptive capacity and tolerance level are important factors in the development or absence of symptoms, then it is imperative to assess both $\mathrm{DAD}$ and $\mathrm{CD}$ in individual subjects before and after treatment.

In addition, long-term instrumentation studies with long-term follow-ups are needed to assess the effectiveness of occlusal treatments. Furthermore, deflective occlusal contacts can produce signs and symptoms other than muscle and structural impairment. These include occlusal wear, pulpitis, tooth abfraction, mobility and shifting of teeth, and aggravation of periodontal disease. Properly designed studies will consider these factors as well. And finally, excursive mandibular movements must be studied along with the closure position in the $\mathrm{SCP} / \mathrm{CR}$ and $\mathrm{MIC} / \mathrm{CO}$, for often wear patterns occur in lateral and protrusive positions.

\section{Recommendations for Occlusal Treatment of TM Dysfunction}

A complete diagnosis and conservative treatment are keys to successfully addressing dysfunction over the long term [1] [107] [165] [166]. 


\subsection{Diagnosis}

A clinical history and examination are usually sufficient to indicate that the subject is suffering from TMD. The purposes of making a diagnosis are 1) to differentiate the condition from other conditions and 2) to plan effective treatment. The diagnosis should involve the elimination of other pathology (e.g., caries) which may cause referred pain or aggravate the dysfunction. A clinical assessment of the extent of dysfunction should be noted so that any improvement in the dysfunctional muscles and/or the TM joint can be monitored [1].

\subsection{Treatment}

At present, treatment is best provided by attending to the traumatic, psychological, or occlusal factors that clinically seem to 1) predispose the subject to TMD, 2) precipitate a problem, or 3) prolong a problem Patients whose problems began after an adverse life event need 1) counseling 2) possible medication or drug therapy (e.g. muscle relaxants), or 3) provision of an occlusal stabilization appliance. A caring attitude is important and proper psychological advice is often indicated. The occlusal component may require further investigation if these measures prove unsuccessful.

Many subjects have no obvious etiologic factors to account for their TMD upon initial intra-oral examination of the habitial occlusion (MIC/CO). Most of these would benefit from a detailed analysis of their occlusion. However, occlusal therapy may not always be effective, and there is a danger that the subject may receive extensive, expensive, and inappropriate treatment. Consequently, a consensus of dental practitioners advocates reversible therapy for the treatment of TMD [1] [107] [165] [166], thus eliminating unwanted tooth movement. At present, the sole method with which to diagnose the occlusal factor in dentate subjects is by the patient's response to stabilization splint therapy. Only the fullcoverage stabilization splint, adjusted to give even posterior contacts in the seated axis position (SCP/CR) and anterior guidance in excursive movements, fulfills both of the criteria of reversibility and effectiveness of design [1] [40] [52] [53].

Those subjects who respond to stabilization splint therapy may require no further treatment. However, if the signs and symptoms of dysfunction return following splint removal, an occlusal analysis is indicated. Depending upon the needs of the patient, 1) long-term stabilization splint therapy, 2) occlusal adjustment, 3) restoration, 4) orthodontic therapy, or 5) orthognathic surgery may be options to provide a stable occlusion that is within the patient's adaptive capacity or tolerance level. This requirement obviously cannot be assessed until dysfunction has been reduced as far as possible by conservative means [1].

\section{Faulty Methodology Leads to Erroneous Conclusions}

Numerous studies have attempted to infer condylar displacement 1) through intraoral visual estimation of the DAD between the SCP/CR and MIC/CO at the occlusal level, 2) through an assessment of study models hand articulated in 
$\mathrm{MIC/CO}$, or 3) radiographically. These studies have found either weak or no association between occlusal factors and TMD [100] [101] [112] [118]-[129] [150] [167] [168] [169] [170] [171]. For example, Pullinger et al., [124] [125] evaluated 222 dental and hygiene students in a study utilizing a questionnaire, intraoral visual estimation (clinical exam), and study models hand articulated in MIC/CO and found no definite relationship between TMD and occlusal factors, such as the DAD between the retruded contact position (RCP) and the intercuspal position (ICP). However, the RCP was determined by passive mandibular manipulation and by study models hand-articulated in MIC/CO. Deprogramming was not utilized and no instrumentation was used to determine the SCP/CR or evaluate condylar position as dictated by the occlusion. Thus, the possible effect of the neuromusculature was not considered.

In their review of the literature, McNamara et al., [171] found a relatively low association between occlusal factors and signs and symptoms of TMD. They concluded that although treatment to a gnathologic ideal was desirable, failure to so treat would not result in TMD. In the studies that they reviewed the occlusion was evaluated by chin-point manipulation and intraoral visual estimation (clinical exam). No attempt was made to override the effects of the neuromusculature (that is, no deprogramming was conducted), and condylar position was determined by radiographic evaluation-not by using dental instrumentation to accurately determine the SCP/CR and resultant DAD.

Lindauer et al. [172] "geometrically constructed" the center of mandibular rotation from Dolphin Digital images (instead of lateral cephalograms) of eight subjects and found that none of these subjects had a center of mandibular rotation (terminal hinge axis) located in the condyle. They concluded that "this finding supports the theory of a constantly moving, instantaneous center of jaw rotation during opening," (p. 577) implying that location of the terminal hinge axis is not reliable for use in predictable dental treatment planning or treatment. This is contrary to the conclusion reached by the overwhelming majority of occlusion investigations published in the dental literature over the last 70 years. Upon closer inspection of the data, however, Lindauer found that the constructed center of mandibular rotation was different not only in every subject, but in the same subject every time it was measured. It would be difficult to reach this conclusion if the researchers had used simple dental instrumentation (articulator-mounted study models and condylar position instrumentation) instead of geometrically constructing the center of rotation.

Braun et al. [173] estimated condylar position with "enhanced sagittal cephalometry" (instead of corrected tomography) and mandibular manipulation alone (after leaf guage deprogramming) instead of using simple dental instrumentation. He concluded that " $\mathrm{CR}$ is not a habitually-assumed position, it is not a functional position, and it is not static or reproducible. An isolated hinge axis does not exist." And finally, "mandibular manipulation and leaf gauge positioning are not effective in seating the condyles-both 'methods' revealed considerable variation of condylar location within the fossae" (p. 37). Again, these conclu- 
sions run contrary to the conclusions found in the overwhelming majority of occlusion investigations published in the dental literature [1] [2] [11] [12] [15] [23] [25] [26] [30] [31] [33] [34] [35] [36] [42]-[49] [51] [52] [53] [56]-[93] [103] [114] [115] [116] [117] [130]-[158] [163] [167] [177]-[200].

Thus it is apparent that there are serious conceptual and methodologic problems with occlusion research that can lead to erroneous or flawed conclusions. The conclusions of these studies, based on faulty methodology, reinforce the need for a standardized methodology for determining condylar position. Considerable variation of condylar position can be produced depending upon the methodology utilized, the least accurate being intraoral visual estimation of the DAD between the SCP/CR and MIC/CO at the occlusal level, assessment of study models hand articulated in MIC/CO, radiographic imaging, or scans. Deprogramming, accurate registration of the SCP/CR, articulator-mounted study models, and condylar position instrumentation are required to determine condylar position accurately in three dimensions.

\section{Occlusal Factors and Condylar Displacement as Possible Etiologic Factors in TMD}

Yet even in investigations using methodology that does not meet the above suggested criteria, occlusal factors have been implicated as possible etiologic factors in TMD [10] [22] [26] [31] [33] [34] [35] [47] [49] [103] [130]-[158] [168] [169]. For example, many studies have shown that the overwhelming majority of human subjects exhibit an initial occlusal contact on a posterior-most tooth [25] [33] [34] [56] [63] [64] [73]-[79] [81] [82] [83] [84] [114] [115] [116] [117] [174] [175] [176]. Study models hand articulated in MIC/CO do not reflect this scientific finding. Yet balancing interferences have been positively correlated with signs and symptoms of TMD, [146]-[155] while larger "slides" (DAD) between the SCP/CR and MIC/CO are regarded as possible etiologic factors in TMD, because these dental arch displacements are more likely to include a significant lateral component [26] [140] [156] [157] [158] [159] [160] [168] [169] [171]. The lateral DAD is particularly prevalent in posterior cross bite.

Egermark-Eriksson et al., [177] in a study of 240 subjects, utilized only intraoral visual estimation to conclude that TM joint sounds were positively correlated with lateral deviation of the mandible (DAD) between the RCP/CR and ICP/CO in all age groups, and that TM joint sounds were positively correlated with unilateral contact in the RCP/CR, findings that have been duplicated in other studies of both children [135] and adults [146] [150] [168] [171]. They concluded that "these associations between unstable occlusion in the RCP/CR and ICP/CO and TM joint sounds may deserve closer experimental study" (p. 70). Magnusson and Carlsson, [49], in a study of 9 subjects, utilized chin-point guidance only to position the mandible, determine occlusal contacts, and perform occlusal adjustment intraorally. They found that 6 weeks postadjustment 7 of the 9 subjects reported a decrease in TMD signs and symptoms and concluded that "by the use of simple principles and procedures occlusal adjustment 
is beneficial in treatment of TM dysfunction" (p. 709). However, utilizing this intraoral method-ology, they also found a "surprisingly high percentage of subjects with occlusal interferences 1 year post-adjustment" (p. 709).

Surprisingly few studies have utilized the methodologic recommendations described above (deprogramming of the neuromusculature, diagnostic study casts articulator mounted in the SCP/CR, and condylar position instrumentation). Even fewer studies have conducted a three-dimensional statistical analysis of condylar position in the SCP/CR as compared to MIC/CO utilizing condylar position instrumentation in either asymptomatic or symptomatic subjects.

\subsection{Deprogramming}

To date, few studies of dental arch spatial relations and condylar position have incorporated neuromuscular deprogramming prior to registering the SCP/CR. This is an important consideration, for the neuromusculature may change the arc of closure of the mandible in the presence of occlusal interferences, in order to protect the interfering teeth from absorbing the entire force of the closing musculature [33] [45] [56] [57] [62] [68] [79] [84] [85] [86].

The usefulness of an adjunct deprogramming procedure depends on three factors. These are ease of fabrication, cost-effectiveness, and minimal patient compliance required to render it effective. Dawson [85] and Slavicek [64] advocate having the patient bite on cotton rolls for deprogramming prior to registering the SCP/CR. The anterior jig advocated by Lucia [89]; the leaf gauge advocated by Long [90], Williamson [80], Woeffel [92], and others [50] [70] [71] [87] [88] [91]; and the anterior flat plane jig utilized by Calagna [69], Karl and Foley [84], and Greco and Vanarsdall [178] are examples of registration techniques incorporating anterior deprogrammers, which separate the posterior teeth, deprogram the neuromusculature, and eliminate premature occlusal contacts and tooth interferences that guide the mandible into $\mathrm{MIC/CO}$.

Calagna evaluated four neuromuscular conditioning techniques-the insertion of cotton rolls, and deprogramming with either the myomonitor, an anterior jig, or a maxillary biteplane. He found that deprogramming with the maxillary biteplane revealed a condylar displacement that was, on average, twice the displacement found with the other three methods, all of which found comparable displacements [69]. Greco and Vanarsdall found that the function of the masseter and temporalis muscle muscles significantly decreased after the patient wore a Hawley biteplane or superior repositioning splint 8 hours per day for 2 weeks [178]. Karl and Foley, utilizing deprogramming and condylar position instrumentation, found a larger discrepancy between the SCP/CR and MIC/CO than had been reported previously by using a hard anterior flat plane jig for deprogramming prior to registering the SCP/CR. They also found that while there was an $18 \%$ chance of detecting a condylar displacement of more than $2 \mathrm{~mm}$ in either the horizontal (AP) or the vertical (SI) direction with the Roth two-piece wax registration technique alone, this percentage more than doubled (to 40\%) with the addition of a hard anterior deprogramming appliance prior to registra- 
tion of the SCP/CR. They concluded that deprogramming provides a registration of condylar position that reveals a greater condylar displacement from MIC/CO than a registration taken without prior deprogramming [84].

\subsection{Splint Therapy}

Splint therapy has proven to be the most effective technique for deprogramming the neuromusculature [33] [45] [48] [50] [62] [69] [70] [71] [79] [84] [85] [86] [178]. Studies [10] [46] [48] [50] [51] [54] [57] [69] [70] [71] [79] [84] [86] [93] [159] have shown that properly conducted splint therapy and/or neuromuscular deprogramming reveals previously undetected occlusal contacts as a result of masticatory muscle relaxation and subsequent mandibular repositioning. The most reliable deprogramming is achieved through full-time wear of a full-coverage upper stabilization splint constructed in the SCP/CR, especially in patients who present with signs and symptoms of TM dysfunction [52] [53].

Williamson utilized condylar position instrumentation with true hinge axis recordings and studied the effect of full-time wear of a full-coverage upper stabilization splint on the location of the mandibular hinge axis in both asymptomatic and symptomatic subjects. He found that the axis moves anterior-superiorly with deprogramming, and that the axis locations following two different periods of stabilization splint wear were highly reproducible. Williamson concluded that "with relaxed musculature [e.g., deprogramming] the hinge axis location is highly reproducible... In the presence of erroneous maxillo-mandibular skeletal relationships, inaccuracy is inherent for occlusal alteration [occlusal adjustment, restorative, orthodontics]." Fifteen of the 16 symptomatic subjects increased their maximum opening following stabilization splint therapy [79].

Johnston and Huffman [93] deprogrammed 92 orthodontically treated subjects and 83 controls with full-time wear of a full-coverage upper stabilization splint and found that the mean DAD for both groups, as measured from articulated study models, was slightly higher than that found in previous studies. They attributed this finding to "unmasking the discrepancy with splint wear." They concluded by advocating that "occlusal treatments (occlusal adjustment, restorative, orthodontics) be designed not necessarily to eliminate centric slides but rather to avoid any increase in the pre-treatment slide" (p. 715), meaning that occlusal treatments should result in no increase in the condylar displacement present pretreatment.

Occlusal splint therapy has been shown to be an effective treatment in the relief of symptoms associated with craniomandibular disorders [40] [179]. Kemper and Okeson also proved that it is an effective treatment modality for the relief of common muscle contraction headache (CMCH) pain [180]. In their 1983 study, 33 subjects with at least one headache a week were treated for 4 weeks with full-time wear of a full-coverage upper stabilization splint. Of these subjects, $63.6 \%$ reported a decrease in the frequency of headaches, and $30.3 \%$ reported complete elimination of headaches. No patient reported an increase in the frequency of headaches. For the group, the average number of headaches per week 
before treatment was 5.06; after occlusal splint therapy the average number of headaches per week was $2.15(P<0.001)$. The authors concluded that occlusal splint therapy can be useful in the diagnosis and treatment of headache $(\mathrm{CMCH})$ pain.

In 1989 Girardot [33] deprogrammed 19 symptomatic subjects with full-time wear of a full-coverage upper stabilization splint until symptoms were relieved and tracked condylar position before and after splint therapy with measurements obtained with condylar position instrumentation (MPI, Great Lakes Orthodontics, Tonawanda, NY). He proved that decreasing the condylar displacement (seating the condyles with stabilization splint therapy) positively correlated with the relief of TM dysfunction $(P<0.001)$.

The investigation by Wahlund and List was a randomized, prospective clinical trial to determine the effectiveness of a flat-plane occlusal stabilization splint, compared to a control splint consisting simply of palatal acrylic. The results showed that stabilization splints are highly effective for the treatment of TMD. First, subjects with the stabilization splint showed a statistically significant improvement in facial pain and headache. Second, subjects with the stabilization splint showed improvement in the intensity of the pain in the joint area compared to subjects with a control splint. Finally, there was a decrease in the need for further TMD treatment with the use of a stabilization splint [181].

\subsection{Instrumentation}

In 1952 Sears [182] studied horizontal, vertical, and sagittal condylar position changes with the condyle migration recorder. The molars of complete-denture patients were set into a supraocclusal position to create a molar pivot, which resulted in patient accommodation by descending the condyle to reduce anterior open bite. Roentgenograms of the condyles were used to correlate the condylar position findings. This was the first study to document the molar fulcrum theory. Long [183] used the Buhnergraph (a stylus adapted to an arcon articulator) to locate the hinge axis, to verify the terminal hinge axis location, and to verify registrations of the SCP/CR. Hoffman [73], using a modified Ney articulator to measure the differences in condylar position between $\mathrm{CR} / \mathrm{SCP}$ and $\mathrm{CO} / \mathrm{MIC}$ in the horizontal (anteroposterior) vertical (superoinferior), and transverse (mediolateral) dimensions in 52 adult subjects, found that the SCP/CR does not correlate with $\mathrm{MIC/CO}$ in the majority of cases.

Williamson, using leaf gauge deprogramming and condylar position instrumentation (Veri-Check, Denar Corporation, Anaheim, California), outlined the rationale for articulating diagnostic study models in the SCP/CR and demonstrated how to measure occlusion-dictated condylar position and condylar displacement in three spatial planes [80]. He used the Veri-Check to analyze variability of CR records [79] [80], and Shafagh [184] [185] used the Veri-Check to compare condylar position using different interocclusal records. Rosner [74] [117] used the modified Buhnergraph for a three-dimensional assessment of condylar position in the RCP and the ICP for 49 and 75 subjects respectively, 
and found a remarkable lack of symmetry for right and left condylar displacement between the two positions. Slavicek [64] described the use of the SAM articulator with the MPI (Great Lakes Orthodontics, Ltd., Tonawanda, New York) to quantify differences between the joint-determined position (SCP/CR) and the tooth-determined position of maximum intercuspation (MIC/CO).

In 1989 Girardot [33] deprogrammed 19 symptomatic subjects with full-time wear of a full-coverage upper stabilization splint until symptoms were relieved, and tracked condylar position before and after splint therapy with measurements obtained with condylar position instrumentation (MPI, Great Lakes Orthodontics). Study casts articulated post-stabilization splint therapy revealed premature occlusal contacts/occlusal interferences on the distalmost molars in all 19 subjects. The nature of condylar displacement in TMD patients was found to be primarily downward (inferior) and backward (distal) and secondarily downward (inferior) and forward (anterior). The condyles moved superiorly as symptoms were relieved with stabilization splint therapy $(P<0.001)$. Stabilization splint therapy was shown to be an effective modality to reduce symptoms related to structural and/or functional disharmony in the gnathic system. This finding led Girardot to conclude that TMD may be related to the occlusion, since closure of the mandible to the intercuspal position in the presence of a posterior occlusal interference can displace the condyle away from the optimal anterior-superior position within the glenoid fossa. Girardot also compared condylar position measurements obtained with condylar position instrumentation to those obtained with oriented (corrected) tomograms and concluded that the registration of condylar position with MPI instrumentation was more accurate than tomographic representation of condylar position $(P<0.001)$, thus questioning the validity of using tomograms as a means of measuring condylar displacement and changes in condylar position.

Alexander [75] studied condylar position in 1993, comparing MPI instrumentation to MRI imaging. He concluded that MIC/CO and SCP/CR are distinctly different condylar positions, with MIC/CO being inferior to SCP/CR. He further concluded that the articulator analysis of MIC/CO and SCP/CR is statistically replicable, thus confirming that the MPI system accurately represents condylar position in three planes. Wood and Elliott found that the two-piece power centric wax registration technique is highly reproducible [63]. In Shildkraut's sample of 131 consecutive patients, $52 \%$ (68) had a condylar displacement of $\geq 2 \mathrm{~mm}$ in either the horizontal (A-P) or the vertical (S-I) plane, and $25 \%$ (33) had a condylar displacement of $\geq 3 \mathrm{~mm}$ [114]. Utt measured the discrepancy between the SCP/CR and MIC/CO in 107 patients before orthodontic therapy with MPI instrumentation and found that $18.7 \%$ of the patients had S-I or A-P condylar displacements of at least $2 \mathrm{~mm}$ on one or both sides. He found that $15.9 \%$ of the patients had transverse (medio-lateral) shifts at the condylar level of $0.5 \mathrm{~mm}$ or greater. No correlation was found between the frequency, magnitude, or direction of condylar displacement and patient age, gender, Angle's classification, or ANB angle. Thus these parameters are not accurate pre- 
dictors of condylar displacement [76].

Crawford used the Panadent articulator with the Panadent Condylar Position Indicator (CPI; Panadent, Grand Terrace, CA) to measure condylar position and concluded that a very strong, statistically significant relationship exists between occlusion-dictated condylar position and signs and symptoms of TMD $(P<$ 0.001 ) [34]. In 2001 Girardot proved that there is a statistically significant greater condylar displacement in hyperdivergent facial skeletal types than in hypodivergent facial skeletal types $(P<0.01)$, in both the horizontal and vertical planes [82]. In 2002 Hidaka measured the condylar displacement present in pretreatment Japanese orthodontic patients. Of 150 patients, 38.7\% (58) had a Horizontal or Vertical displacement of $\geq 2 \mathrm{~mm}$ or a transverse displacement of $\geq 0.5 \mathrm{~mm}$. This led him to conclude that orthodontists should be aware of a high incidence of condylar displacement in pretreatment Japanese orthodontic patients which could aid in more accurate diagnosis of skeletal and dental discrepancies [78].

\section{Reproducibility of the Registration Technique}

Alexander found that the articulator analysis of MIC/CO and the SCP/CR is statistically replicable [75], and Shafagh [184] [185], using deprogramming and the Veri-Check to compare condylar position produced by different interocclusal records, determined that the condylar RCP (retruded contact position/SCP/CR) has a variability in any three planes of space of $\pm 0.2 \mathrm{~mm}$. Rosner found the condylar position measurements to be accurate to $0.15 \mathrm{~mm}$ [74] [117] [144]. The high reproducibility of the SCP/CR registration technique was confirmed by Wood and Elliott [63]. Hicks and Wood demonstrated that the condylar registrations produced by the SAM MPI and Panadent CPI condylar instrumentation systems are reproducible on the same patient [116].

Measurement error for each directional component of the graphic recordings for condylar position are given in Table 2, which presents 8 previous investigations of this type conducted over a 24 -year period, all of which reported measurement error of $\leq 0.3 \mathrm{~mm}$.

Table 2. Reliability of the registration and laboratory technique: Error measurements of condylar Position in 3 Planes: 8 studies conducted over a 24 year period.

\begin{tabular}{cccc}
\hline \multirow{2}{*}{ INVESTIGATOR YR } & \multicolumn{3}{c}{ COMPONENT and ERROR (mm) } \\
\cline { 2 - 4 } & AP (HORIZ) & SI (VERT) & ML (TRANS) \\
\hline SHAFAGH '79 & 0.15 & & 0.23 \\
ROSNER '86 & 0.16 & 0.16 & \\
WOOD + KORNE '92 & 0.19 & 0.21 & 0.10 \\
WOOD + ELLIOTT '94 & 0.27 & 0.30 & 0.19 \\
UTT '95 & 0.25 & 0.25 & \\
KARL + FOLEY '99 & 0.17 & 0.19 & 0.08 \\
GIRARDOT '01 & 0.25 & 0.25 & 0.16 \\
CORDRAY '06 & 0.15 & & \\
\hline
\end{tabular}


The accuracy and repeatability of the MPI instrument was proven by Wood and Korne [115], who found the instrument error of the MPI system to be \pm 0.2 $\mathrm{mm}$ for each component in the horizontal and vertical planes. They also determined that measuring condylar displacements with condylar position instrumentation utilizing either the estimated or the true hinge axis to mount the maxillary cast is highly reproducible. In other words, the recording of condylar displacements with condylar position instrumentation was proven to be highly repeatable, regardless of the hinge axis used. Because of its practicality and reliability, these authors recommended use of the estimated hinge axis for examining the mandibular position of mounted diagnostic casts and for producing MPI condylar position values with which to convert lateral cephalograms taken in $\mathrm{MIC/CO}$ to SCP/CR cephalograms. However, for the study of mandibular movements, for diagnostic and definitive equilibration, for extensive restorative reconstruction, and for maxillary surgical movements resulting in autorotation of the mandible, they recommended that only the true hinge axis be used.

\subsection{The Relationship between DAD (Dental Arch Displacement/Occlusal Slide/Functional Mandibular Shift) and Three-Dimensional Condylar Displacement}

A source of confusion in occlusion research has been that the nature of the apparent shift at the level of the occlusion (the DAD between the SCP/CR and $\mathrm{MIC} / \mathrm{CO}$ ) does not accurately reflect the three-dimensional nature of the displacement at the level of the condyles (CD) [33] [34] [35] [58] [63] [73]-[79] [81] [82] [83] [84] [85] [113] [114] [115] [116] [117]. Hodge and Mahan showed that only a small part of the AP component of a DAD (SCP/CR-to-MIC/CO occlusal slide) as seen at the incisal level is due to AP translational displacement of the condyles. The majority of the AP component of the DAD ("slide") seen at the incisal level is due to "the mandible swinging posteriorly when it opens and anteriorly when it closes, as it rotates around the horizontal axis in the terminal hinge closing arc" ([186], p. 419).

Rosner states, "The difficulty in aligning occlusal landmarks in a sagittal plane when a slide (displacement) from the SCP/CR to the MIC/CO position is present does not entirely reflect the amount of translation of the hinge axis between those two points. In the null line significant translation of the hinge axis can occur due to rotation of the mandible without obvious movement in the anterior region of the dentition" ([74], p. 717).

Rosner and Goldberg further state, "From our analysis of the condylar position in three dimensions, it is difficult to determine asymmetric condylar movement when measuring the dental midline displacement between the SCP/CR and $\mathrm{MIC/CO}$. The complex way that movement is transmitted to the condylar centers of rotation in the form of skew, tilt, length of vertical and horizontal rotational distances, and medial-lateral displacement... [144] in combination with the degrees of freedom [possible] make it difficult to determine condylar movements by observation or measurement of the dental midline displacement be- 
tween the SCP/CR and MIC/CO" ([117], p. 230).

The findings of Rosner's studies [74] [117] [144] support the findings of Hoffman [73], Wood and Korne [115], Utt [76], and Hidaka [78], who also found a remarkable absence of symmetrical condylar displacement between the SCP/CR and MIC/CO.

\subsection{Measurement of Condylar Displacement}

\subsubsection{The Direction of the Condylar Displacement}

The direction of the condylar displacement found in more recent condylar position instrumentation studies (Wood and Korne [115], Wood and Elliott [63], Shildkraut and Wood [114], Utt [76], Girardot [33] [82], Crawford [35], Karl and Foley [84], and Hidaka [78]) has been most commonly posterior-inferior, next-most commonly anterior-inferior, and least commonly straight inferior. These findings support the concept of vertical condylar displacement as a result of posterior premature occlusal contacts [35] [57] [58] [68] [85] [116] [136] [165] [182] [187]. No relationship has been found between the transverse (mediolateral) displacement and either the horizontal or vertical displacements [73] [74] [76] [78] [115] [117] [144].

\subsubsection{The Magnitude of Condylar Displacement}

The magnitude of condylar displacement for an asymptomatic population reported in previous research investigations utilizing models articulated in the SCP/CR and condylar position instrumentation to measure condylar displacement in three planes is given in Table 3 [73]-[78] [82] [84] [115] [116] [117].

The larger discrepancies reported by Karl and Foley [84] and Cordray are most likely due to methodology. Both studies used deprogramming with a hard anterior stop prior to registration of the SCP/CR, which results in more complete condylar seating and more accurate measurement of condylar displacement than are found in those studies which have utilized traditional chin-point guidance alone (without deprogramming) in an attempt to clinically capture the SCP/CR [34] [63] [73]-[78] [80] [83] [114] [115] [116] [117]. Girardot [82] found larger horizontal and vertical condylar displacements in dolichofacial (open-bite) skeletal patterns than in brachyfacial (deep bite) skeletal patterns. The vertical component of the condylar displacement was almost always greater than the horizontal component, and this supports the concept of vertical condylar displacement as a result of posterior premature occlusal contacts [35] [57] [58] [68] [85] [116] [136] [165] [182] [187]. Larger condylar displacements were observed in all dimensions for symptomatic subjects, especially in the transverse (medial-lateral) plane.

\subsection{The Relationship between Displacement and Dysfunction}

\subsubsection{The Relationship between Transverse DAD (Dental Arch Displacement) and TMD}

When analyzing the potential relationship between displacement and TMD, it is important to determine which type of displacement has actually been measured- 
Table 3. Magnitude of condylar displacement in three planes ( $\mathrm{mm})$ as measured from asymptomatic and symptomatic populations.

\begin{tabular}{|c|c|c|c|c|}
\hline \multirow{2}{*}{ INVESTIGATOR (YR) } & \multicolumn{4}{|c|}{ COMPONENT (mm) } \\
\hline & AP (HORIZ) & SI (VERT) & ML (TRANS) & $\mathrm{n}=$ \\
\hline HOFFMAN (1973) & 0.28 & 0.25 & 0.10 & 52 \\
\hline ROSNER (1986) & 0.56 & 0.84 & 0.34 & 75 \\
\hline WONG (Unpub) & 0.70 & 1.00 & 0.30 & 250 \\
\hline WOOD + KORNE (1992) & -- & 1.20 & -- & 39 \\
\hline ALEXANDER (1993) & 0.25 & 0.30 & 0.30 & 28 \\
\hline UTT (1995) & 0.61 & 0.84 & 0.27 & 107 \\
\hline ESMAY (1995) (MS) & 0.63 & 1.53 & 0.37 & 46 \\
\hline HICKS + WOOD (1996) & -- & 1.20 & 0.27 & 37 \\
\hline GIRARDOT (2001) brachyfacial & 0.66 & 1.20 & -- & 19 \\
\hline GIRARDOT (2001) dolichofacial & 1.21 & 1.70 & -- & 19 \\
\hline HIDAKA (2002) & -- & 1.00 & 0.00 & 150 \\
\hline KARL + FOLEY $(1999)^{\star *}$ & 1.54 & 1.76 & 0.51 & 40 \\
\hline WEFFORT (2010) ASYMPT & 0.63 & 1.26 & 0.23 & 35 \\
\hline WEFFORT (2010) SYMPT & 0.64 & 1.60 & 0.41 & 35 \\
\hline CORDRAY (2006) ASYMPT** & 0.86 & 1.80 & 0.26 & 596 \\
\hline CORDRAY (2016) SYMPT** & 1.02 & 2.20 & 0.82 & 596 \\
\hline
\end{tabular}

--: Magnitude either not measured or averaged using - and + values instead of absolute values; ${ }^{* *}$ : Neuromuscular deprogramming utilized prior to registration of SCP/CR; Note: 1) Displacement values for deprogrammed subjects larger than for non-deprogrammed subjects; 2) Displacement values for symptomatic subjects larger than for asymptomatic subjects; 3) Displacement values for dolichofacial patterns larger than brachyfacial patterns.

DAD (dental arch displacement) or CD (condylar displacement). For example, occlusal discrepancies (DAD, slides, and functional mandibular shifts between the SCP/CR and MIC/CO, most often measured intraorally) have been implicated as possible etiologic factors in TMD [26] [31] [33] [34] [35] [47] [49] [103] [130]-[158] [167] [169] [171], but a discrepancy at the level of the occlusion gives no information on the three-dimensional nature of the discrepancy or displacement at the level of the condyles [33] [34] [35] [58] [63] [73]-[79] [81] [82] [83] [84] [85] [113] [114] [115] [116] [117]. Nevertheless, studies that have attempted to measure DAD between the SCP/CR and MIC/CO intraorally have inferred that $\mathrm{CD}$ as a result of $\mathrm{DAD}$, especially in the transverse plane, which commonly presents with dental cross bite, may be an etiologic factor in TMD.

Larger slides between the SCP/CR and MIC/CO have been regarded as possible etiologic factors in TMD because they are more likely than smaller slides to include a significant lateral component [26] [140] [156] [157] [158] [167] [169] [171], which is common in association with dental cross bite. Occlusion texts 
have noted the potential significance of a transverse (medial-lateral) DAD in the production of TMD [11] [25] [56] [57] [62] [66] [85] [87] [188], and this is supported by numerous independent research investigations. Reider's epidemiologic survey led him to conclude that "the considerable prevalence $(25 \%=81 / 323)$ of transverse mandibular displacement (DAD) in a diversified sample $(n=323)$ emphasizes the need for recognition and analysis of the etiologic factors in occlusal mandibular dysfunction" ([158], p. 299). Solberg found a higher prevalence of TMD signs and symptoms in subjects with a transverse DAD between the SCP/CR and MIC/CO $(P<0.01)$. Asymmetry in the DAD was observed in $15.6 \%$ of the 739 subjects examined intraorally. Significantly more dysfunctional subjects had asymmetrical DAD $(P<0.01)$, and subjects with larger DAD tended to have longer, asymmetrical dental arch displacements $(P<0.01)$. Tenderness of the TMJ and capsule was associated only with asymmetrical DAD $(P<0.01)$. These findings suggest that the direction of the DAD - that is, its lack of symmetry-is of greater clinical importance than its magnitude in the production of dysfunction [1] [151].

Droukas found that $27 \%$ of his sample $(n=48)$ had a transverse (medio-lateral) DAD of $>0.5 \mathrm{~mm}$ at the occlusal level [163]. Egermark-Eriksson observed that TMJ sounds positively correlated with lateral deviation of the mandible between the SCP/CR and MIC/CO in all age groups $(\mathrm{n}=240)(P<0.01$ ages $11-$ 15; $P<0.001$ age 20) [177]. From a sample of 4724 children 5 to 17 years old, Thilander et al. proved that mediolateral DAD was significantly associated with clicking $(P<0.001)$, temporalis muscle tenderness $(P<0.01)$, and TM joint pain $(P<0.01)$. Non-working-side interferences (as observed clinically) were significantly associated with clicking $(P<0.01)$ and masseter and temporalis muscle tenderness $(P<0.01)$. TMD was significantly associated with posterior crossbite, anterior open bite, Angle's Class III malocclusion, and extreme maxillary overjet, leading them to conclude that "sliding [displacement] of the mandible (DAD) laterally from SCP/CR to MIC/CO will explain the significant association between TM dysfunction and posterior crossbite, and hence the association with clicking and muscle tenderness" ([189], p. 153). Egermark proved that "lateral forced bite" (transverse or mediolateral mandibular displacement/DAD) and unilateral crossbite were positively correlated with TM dysfunction signs and symptoms $(P<0.01)$ and considered them to be potential risk factors in the development of TMD [190]. Mohlin observed that dental crossbite was more common in TMD patients than in controls [191]. Lindblom [192] and Mongini [193] have published clinical techniques for the treatment of transverse (mediolateral) DAD. Thus, it has been clearly shown that transverse (mediolateral) DAD, commonly associated with dental cross bite, is positively correlated with TM dysfunction signs and symptoms.

\subsubsection{The Relationship between $C D$ (Condylar Displacement) and TMD}

As stated previously, it is important to differentiate which type of displacement has been actually measured-DAD or $\mathrm{CD}$, when analyzing the potential rela- 
tionship between displacement and TMD. The relationship between DAD and TMD has been studied at length and with large population studies, as shown above. The body of research on the relationship between CD and TMD is much smaller due to the limitations listed previously with regard to the use of neuromuscular deprogramming and dental instrumentation.

\subsubsection{Condylar Displacement Studies Utilizing Radiography}

Radiographic studies of condylar position have inferred that condylar displacement may be an etiologic factor in TMD. Weinberg, using transcranial radiography, reported on the role of condylar position in TMD and emphasized the importance of condylar position in the diagnosis and treatment of TMD and pain. He found that the $71 \%$ of the condyles measured in TMD subjects were displaced distally and defined condylar concentricity within the fossa as the optimal condylar position [141]. Mongini reviewed the role of radiography in the diagnosis of TMD dysfunction and the significance of condylar displacement in gnathic dysfunction, muscle dysfunction, and muscle pain [194]. Krueger and Dale described a means of transferring information from transcranial radiography to articulator instrumentation and projected condylar displacement as an etiologic factor in TMD [195]. Maruyama et al. studied the relationship of the $\mathrm{SCP} / \mathrm{CR}$ to MIC/CO using the mandibular kinesiograph (Myotronics, Incorporated, Seattle, Washington) in normal and TMD subjects. The deviation from the SCP/CR to MIC/CO in the TMD group was twice that for normal subjects in all three planes, leading the authors to conclude that the "tooth contact slide" [DAD] can cause TMD because mandibular position is dictated by occlusal contacts [170]. Williams compared symptomatic and nonsymptomatic TM joints using laminagraphs (corrected tomograms) and found significantly more condylar displacement in symptomatic subjects. He suggested that a submental vertex film be used to more accurately determine a consistent depth of cut of the condylar image [142]. Weinberg discussed the role of stress, occlusion, and condylar position in TMD and suggested that condylar position plays an important role in the diagnosis and treatment of TMD [196].

\subsubsection{Condylar Displacement Studies Utilizing Condylar Position Instrumentation}

The most promising research on the relationship between condylar displacement and TMD comes from studies that have used condylar position instrumentation to determine condylar position in three dimensions. Of the studies utilizing instrumentation, Rosner calculated the angular values of the least-squares straight lines for condylar positions in the $y$ (vertical = SI) axis. When the angular difference of the right and left sides was compared between a group of subjects with primary symptoms and mandibular dysfunction and a group of subjects without primary symptoms, there was a more than 16 -fold increase in the angular difference for the group of subjects with primary symptoms and mandibular dysfunction [117] [144].

Utt [76] set criteria for an abnormal or excessive magnitude of condylar dis- 
placement by doubling the mean values he observed. Using these criteria, he noted that $19 \%$ of his sample of 107 subjects had a condylar displacement of $\geq 2$ $\mathrm{mm}$ horizontally or vertically. Similar studies have shown a range from $16 \%$ to $52 \% \geq 2 \mathrm{~mm}$ horizontally or vertically (Hidaka [78], 16\%; Utt [76], 19\%; Esmay [77], 33\%; Shildkraut [114], 52\%). In Hidaka's sample, 38.7\% (58/150) had a horizontal or vertical displacement of $\geq 2 \mathrm{~mm}$ or a transverse displacement of $\geq 0.5$ $\mathrm{mm}$ [78]. In Shildkraut's sample of 131 consecutive patients, 52\% (68) had a condylar displacement of $\geq 2 \mathrm{~mm}$ in either the horizontal or vertical plane and $25 \%$ (33) had a condylar displacement of $\geq 3 \mathrm{~mm}$ [114].

Girardot, using the MPI, found that the condyles were displaced inferiorly in the majority of TMD patients and that symptoms were alleviated as the condyles moved toward a more seated position $(P<0.001)$ [33]. Cacchiotti observed that the MPI-measured discrepancies between the SCP/CR and MIC/CO of subjects with TMD complaints were significantly larger than those of a control group consisting of dental students without TMD complaints [197].

Crawford's study [34] represents a landmark breakthrough in occlusion research, utilizing many of the research recommendations presented previously. The rationale for his study were the facts that "very few studies have examined occlusion-dictated condylar position using instrumentation and none have compared an "ideal" sample against an untreated control group with regard to TM dysfunction signs and symptoms" (p. 103). In this study a written patient history, clinical exam, and CPI measurements (Panadent articulator) were used to compare TMD symptomatology and CPI values of an experimental sample of 30 subjects with "ideal" occlusions. The sample was selected from a population that had undergone full-mouth reconstruction using gnathologic principles that included the SCP/CR coincident with MIC/CO and a mutually protected occlusal scheme. This ideal sample was compared against a control sample consisting of 30 untreated subjects from the general population selected to match the ideal sample as closely as possible according to sex (same number of men and women). A duplicate written exam [anamnestic questionnaire] was given to the subjects in the restored ideal sample to assess TMD symptoms prior to reconstruction. The amount of time post-reconstruction averaged 10.6 years and ranged from 2 to 23 years.

In this study the concept of deprogramming was employed, as the restored ideal sample underwent full-time splint wear until the subjects were asymptomatic and stabilized prior to reconstruction. Instrumentation was utilized to articulate and reconstruct the dental arches in the SCP/CR position and to measure condylar displacement throughout the process. This was a long-term instrumentation study with long-term follow-ups (2 to 23 years) to assess the effectiveness and stability of occlusal reconstruction. The TMJ evaluation consisted of two parts: an anamnestic evaluation and a clinical exam, both based on the Helkimo index. In addition, the reconstructed group completed an anamnestic (retrospective) questionnaire evaluating TMD symptoms prior to reconstruction. 
Crawford documented a high correlation $(P<0.001)$ between signs and symptoms of TMD and increased condylar displacement. First, he found that in the restored ideal group there was an $84 \%$ reduction in symptoms posttreatment; the number of subjects reporting severe symptoms decreased from 16 to 1 ; the number of subjects reporting no symptoms increased from 8 to 18 ; and no subject showed an increase in anamnestic score. These findings are especially important in light of the fact that the treated subjects were an average of 10.6 years post-reconstruction, with a range of 2 to 23 years.

Second, Crawford found that average anamnestic scores were much higher in all groups where condylar displacement was greater than $1 \mathrm{~mm}$, and that this finding was statistically significant $(P<0.001)$.

Third, Crawford documented a very strong statistically significant relationship $(P<0.001)$ between condylar displacement and TMD signs and symptoms in all of the subjects of the study. As the magnitude of condylar displacement increased, TMD symptoms increased. The magnitude of condylar displacement and symptoms (both clinical and anamnestic) was significantly smaller in the restored ideal group than it was in the untreated control group.

Fourth and finally, Crawford found that occlusal attrition was less prevalent in the restored ideal group than it was in the untreated control group. This is especially important in light of the fact that 8 of the 30 restored ideal subjects underwent full-mouth reconstruction specifically to restore tooth material lost as a result of severe wear and attrition (cusps worn to the gingival level).

The clinical implications of Dr. Crawford's study are as follows:

1) SCP/CR is a desirable treatment goal for reorganization of the occlusion. It is especially desirable in the following cases:

- When restoring posterior occlusal stability by occlusal adjustment or tooth restoration.

- When treating mandibular dysfunction.

- When restoring the dentition with multiunit restorations.

- When treating patients with complete denture prosthetics.

- When treating patients orthodontically.

- When positioning the condyle during orthognathic surgery.

2) When occlusal correction is performed accurately (that is according to the methodologic principles outlined in this paper) it is clear that the correction of both the occlusion and condylar position is remarkably stable.

3) An individual's tolerance to condylar displacement may be less than previous studies have suggested and is certainly less than has been previously understood in the field of dentistry.

4) Orthodontic cases should be compared to gnathologically restored cases, not to an untreated population.

5) Since an increase of condylar displacement (CPI value) from 1 to $2 \mathrm{~mm}$ was shown to aggravate symptoms of TMD dramatically, it may be in the patient's best interest for the clinician to reduce or minimize the pretreatment condylar displacement as much as possible. 


\subsubsection{The Relationship between Transverse (Medio-Lateral) CD (Condylar Displacement) and TMD}

The nature of the apparent DAD at the level of the occlusion does not accurately reflect the three dimensional nature of the displacement at the level of the condyles [33] [34] [35] [58] [63] [73]-[79] [81] [82] [83] [84] [85] [113] [114] [115] [116] [117]. It has been postulated in occlusion circles that a transverse (mediolateral ) $\mathrm{CD}$ of $\geq 0.5 \mathrm{~mm}$ is the most clinically critical type of displacement and is significant in the production of signs and symptoms of TMD [6] [11] [26] [56] [57] [62] [66] [76] [85] [87] [117] [140] [144] [151] [157] [158] [163] [191] [198]. For example, Hansson stated that "medio-lateral (transverse) deflection of the condyles from the seated position is most critical to asymptomatic function" [199]. Yet the number of investigations comparing transverse condylar displacement in asymptomatic and symptomatic populations and utilizing deprogramming and instrumentation is remarkably small. Nevertheless, studies that have attempted to measure the DAD between the SCP/CR and MIC/CO intraorally have inferred that condylar displacement (CD) as a result of dental arch displacement (DAD), especially in the transverse plane, may be an etiologic factor in TMD.

Utt [76] reported that $17 \%$ of his nondeprogrammed asymptomatic sample (18/107) had a transverse (mediolateral) condylar displacement of $\geq 0.5 \mathrm{~mm}$, while in Hidaka's nondeprogrammed sample $31.3 \%$ (47/150) had a transverse (mediolateral) displacement of $\geq 0.5 \mathrm{~mm}$ [78]. In Rosner's studies $12 \%$ of the nondeprogrammed sample (9/75) had a transverse (mediolateral) displacement of $\geq 0.6 \mathrm{~mm}$ and this positively correlated with TMD symptoms $(P<0.01)$. Another measure of transverse (mediolateral) displacement (mean index of intercuspal asymmetry) was found to be high $(1.29 \mathrm{~mm})$ [117] [144].

Rosner [117] [144] measured condylar position in 75 subjects using the Whipmix articulator and the modified Buhnergraph instrument. Condylar position data were collected and organized into scattergram form, from which he created a sagittal peripheral outline (SPO) of condylar position measurements. The dimensions of the SPO were determined by nearly tripling the average horizontal $=\mathrm{AP}$ displacement found $(0.5 \mathrm{~mm})$ and doubling the average vertical $=$ SI displacement found $(0.8 \mathrm{~mm})$ to $1.4 \mathrm{~mm}$ and $1.7 \mathrm{~mm}$ respectively. Condylar position data were correlated with a questionnaire and the sagittal condylar positions of symptomatic subjects were found to be located most often outside the SPO, and that these larger displacements positively correlated with joint noise $(P$ $<0.01)$. Of the 26 subjects who reported joint noise, 20 , or $76.9 \%$ were outside the SPO.

According to Rosner's data, subjects with mandibular dysfunction had at least two condylar positional characteristics. First, the condylar position was outside the SPO in symptomatic subjects, In addition Rosner found that noise in the TM joints positively correlated with condylar positions outside of the SPO while condylar positions within the SPO were silent $(P<0.01)$. Second, subjects with mandibular dysfunction exhibited an increased mean index of intercuspal asymmetry ( $1.29 \mathrm{~mm}$ [SD 0.57$])$. The index of intercuspal asymmetry was statis- 
tically significant at the $P<0.01$ level between the group of 38 subjects without primary symptoms and the group of 37 subjects with one or more primary symptoms and mandibular dysfunction. The fact that the index of intercuspal asymmetry was statistically significant at the 0.01 level is in keeping with the assertion that lateral $\mathrm{CD}$ is an important finding. The discovery that subjects with one or more primary symptoms had an index of intercuspal asymmetry similar to the mean and SD of subjects seeking treatment of mandibular dysfunction was an unexpected finding. The smallest values for mediolateral $\mathrm{CD}$ were seen in subjects without primary symptoms [117] [144].

Cordray [200] [201], utilizing chairside deprogramming and instrumentation, determined the DAD and CD for 596 consecutive asymptomatic subjects and 596 consecutive symptomatic subjects presenting for orthodontic treatment. The objective was to evaluate the three-dimensional nature of dental arch displacement (DAD) and condylar displacement (CD) between the seated condylar position (SCP) and the intercuspal position (ICP) and to compare results derived from large deprogrammed asymptomatic and symptomatic populations. DAD and CD were increased from the ICP (MIC/CO) to the SCP/CR in all 1192 subjects and also increased for symptomatic subjects. These displacements were statistically significant and clinically significant. Specific findings are as follows:

1) In $1122 / 1192=94.1 \%$ of the total sample (CI 92.1, 96.0) of asymptomatic and symptomatic subjects the initial occlusal contact occurred on the posterior-most tooth in the SCP/CR. Traditional dental casts collected for diagnosis and treatment planning which are hand-articulated into intercuspation do not reflect this scientific fact.

2) The three-dimensional study of $\mathrm{DAD}$ in the SCP/CR as compared to the $\mathrm{DAD}$ in MIC/CO revealed:

a) Horizontal (AP): Mandible more retrusive posteriorly, possible change in occlusion pattern/classification at the canine or first molar. Increased incisor overjet (OJ) anteriorly;

b) Vertical (SI): Bite more open (decreased incisor overbite (OB) vertically);

c) Transverse (ML): Dental midlines coincident (unless a dental arch asymmetry or skeletal asymmetry).

3) The three-dimensional study of $\mathrm{CD}$ in the SCP/CR as compared to the CD in $\mathrm{MIC} / \mathrm{CO}$ indicated:

a) The position of the condyles in the ICP/MIC has been proven to be different from the seated condylar position (SCP)/CR [34] [48] [56] [57] [63] [73] [74] [75] [76] [78] [79] [80] [82] [83] [84] [114] [115] [116] [174] [175] [176] [185] [197].

b) The direction of condylar displacement from the SCP to the ICP (MIC/CO) in the total sample was posterior-inferior (65.8\%), anterior-inferior (28.5\%), and straight inferior (4.2\%). These percentages are in close agreement with Crawford [34], Dawson [35], Wood and Elliott [63], Utt [76], Hidaka [78], Girardot [82], Karl and Foley [84], Shildkraut and Wood [114], Wood and Korne [115], and Roth [187] and supports the concept of vertical condylar displacement resulting from posterior initial occlusal contact. 
c) The following clinical findings support the concept of increased mandibular condyle displacement $(\mathrm{CD})$ in subjects with symptomatology (CMCH and TM dysfunction):

- Increased Magnitude of Condylar Displacement in Symptomatic Subjects Mean horizontal (AP) and vertical (SI) condylar displacements were higher than reported previously for an asymptomatic population [34] [63] [73] [75] [76] [78] [80] [82] [83] [84] [114] [115] [117] [144] [176] most likely due to the addition of neuromuscular deprogramming prior to registration of the $\mathrm{SCP} / \mathrm{CR}$, and these displacements increased in the symptomatic sample in all three planes.

Displacements $\geq 1.6 \mathrm{~mm}$ in the horizontal (AP) plane, $\geq 2.0 \mathrm{~mm}$ in the vertical plane (SI), and $\geq 0.5 \mathrm{~mm}$ in the transverse (ML) plane have been considered clinically significant [34] [63] [76] [78] [82] [84] [114]. Nearly all symptomatic subjects $(96.9 \%=578 / 596)$ exhibited a significant $($ vertical $=$ SI $\geq 2.0 \mathrm{~mm}$, horizontal $=\mathrm{AP} \geq 1.6 \mathrm{~mm}$, or transverse $=\mathrm{ML} \geq 0.5 \mathrm{~mm}$ ) condylar displacement in at least one plane. The magnitude of horizontal (AP) or vertical (SI) displacement was $\geq 2 \mathrm{~mm}$ in $53.6 \%$ of asymptomatic subjects and increased to $73.3 \%$ of symptomatic subjects. This incidence is larger than reported previously (Utt [76] (19\%) Hidaka [78] (16\%)). 22.9\% of asymptomatic subjects had condylar displacements of $\geq 3 \mathrm{~mm}$ horizontally (AP) or vertically (SI) and this is in agreement with Shildkraut and Wood [114] who found $25 \%$ (33/131) to have a discrepancy of $\geq 3 \mathrm{~mm}$. This nearly doubled to $39.7 \%$ of symptomatic subjects.

- Significant Condylar Displacement and Its Relation to Occlusion Classification Change:

$26.6 \%$ of asymptomatic subjects displayed a significant condylar displacement ( $\geq 2 \mathrm{~mm} \mathrm{SI}, \geq 1.6 \mathrm{~mm} \mathrm{AP}$, or $\geq 0.5 \mathrm{~mm} \mathrm{ML}$ ) and change in occlusion pattern/classification at the canine or first molar between the SCP and the ICP. This increased to $63.7 \%$ of symptomatic subjects, indicating increased frequency and magnitude of both dental arch displacement (DAD) and condylar displacement (CD) in symptomatic subjects.

- Increased Magnitude of Transverse Condylar Displacement in Symptomatic Subjects

It has been postulated that TRANSVERSE (ML) condylar displacement of $\geq 0.5 \mathrm{~mm}$ is the most clinically critical type of displacement and is significant in the production of signs and symptoms of $\mathrm{CMCH}$ and TM dysfunction [6] [11] [26] [56] [57] [62] [66] [76] [85] [87] [117] [140] [144] [151] [157] [158] [163] [191] [198] [199]. Mean magnitude of transverse (ML) condylar displacement of asymptomatic subjects $(0.26 \mathrm{~mm})$ increased to $0.82 \mathrm{~mm}$ in symptomatic subjects. $10.7 \%$ of asymptomatic subjects had a transverse (ML) discrepancy of $\geq 0.5 \mathrm{~mm}$-this increased to $87.6 \%$ of symptomatic subjects. This is a clinically significant finding and supports the hypothesis that TRANSVERSE (ML) condylar displacement $\geq 0.5 \mathrm{~mm}$, commonly presenting with dental cross bite [83] [163] [189], may be associated with signs and symptoms of TM dysfunction, most notably muscular hyperactivity and 
common muscle contraction headaches (CMCH) [73] [74] [76] [163] [189].

These findings have been corroborated by three recent independent internationally published reports utilizing similar methodology (dental instrumentation and condylar displacement measurements) and support the postulate that condylar displacement, especially in the transverse plane, is etiologic for TMD symptomatology.

Weffort and Fantini measured condylar displacement in three dimensions between the SCP/CR and MIC/CO in 35 symptomatic and 35 asymptomatic non-deprogrammed subjects with the Panadent CPI instrumentation and found statistically significant differences between the two groups. The symptomatic subjects had increased condylar displacement in the horizontal, vertical, and transverse planes. The transverse displacement of the asymptomatic subjects was nearly doubled in the symptomatic subjects $(P=0.015)$, who also exhibited increased frequency of bilateral condylar displacement in an inferior and distal direction $(P=0.012)$. No statistical difference was noted between genders [202].

He et al. compared an experimental group of 107 symptomatic subjects aged 18 - 32 to a control group of 70 subjects with no signs or symptoms of TMD aged 20 - 30 years. A positive CD (exceeding $1 \mathrm{~mm}$ in the vertically or horizontally or $0.5 \mathrm{~mm}$ transversely) was found in $72.9 \%$ of the experimental (symptomatic) and $11.4 \%$ of the control (asymptomatic) groups $(P<0.001)$. The CD was significantly correlated with signs and symptoms of TM dysfunction $(P<0.01)$ and the degree of this displacement positively correlated with the severity of signs and symptoms. They concluded that CD may be contributory to the development of TMD and is a reliable indicator of the presence and severity of TMD [203].

Padala et al. found significant deviations at the level of the occlusion in both asymptomatic and symptomatic groups between the SCP and the ICP (MIC/ $\mathrm{CO})$. Average vertical and horizontal condylar displacements were significantly greater in the symptomatic group and the mean transverse CD of the asymptomatic group $(0.61 \mathrm{~mm})$ increased to $0.96 \mathrm{~mm}$ in the symptomatic group. They concluded that mandibular condyle displacement (CD) may play a significant role in the etiopathogenesis of TM disorders [204].

It is not possible to detect a transverse (mediolateral) condylar displacement (CD) by clinical examination (intraoral visual estimation with mandibular manipulation) or manipulation of hand-articulated study casts. Neither is it possible to detect a $0.5 \mathrm{~mm}$ transverse (mediolateral) condylar displacement with joint imaging, either radiographically (with (Posterior-Anterior) cephalograms or joint imaging in the sagittal plane) or by conducting scans (MRI, CT, or $\mathrm{CBCT}$ ) in MIC/CO. Condylar position instrumentation is required to determine transverse (mediolateral) condylar displacements of this magnitude. Previous studies utilizing condylar position instrumentation have measured the frequency of transverse (mediolateral) condylar displacement, but have not related this measurement to the production of dysfunction. In addition, no relationship has been found between the transverse condylar displacement and either horizontal 
or vertical displacement [73] [74] [76] [78] [115] [117] [144].

\section{Conclusions}

The role of occlusion in the development of signs and symptoms of TMD continues to be a source of controversy. There has even been a movement within dentistry over the past few decades to minimize the role of occlusion in TMD and to deemphasize the study of occlusion in dental education. However, this review of the current literature specifies that, despite the fact that the etiology of TMD is probably multifactorial, completely discounting the role of occlusion may be an inappropriate interpretation of published data.

The three-dimensional analysis of dental arch displacement (DAD) and condylar displacement (CD) from the SCP/CR to MIC/CO utilizing articulated study casts and condylar position instrumentation suggests that, although a clear correlation between occlusion and TMD has not been clearly evident in the dental literature due to omission of the specific research principles and techniques outlined herein, it has, nevertheless, been proven in scores of independent research investigations conducted worldwide. A reform of occlusion/TMD research protocol is needed for progress in the field.

Current research conducted according to the principles outlined herein indicates the following:

A prudent goal of clinical dental correction would be to minimize condylar displacement whenever possible. Condylar displacement (CD) for deprogrammed subjects is larger than that for non-deprogrammed subjects. CD for symptomatic subjects is larger than that for asymptomatic subjects. Transverse (mediolateral) $\mathrm{DAD}$ and $\mathrm{CD}$, commonly presenting with dental cross bite, have been shown to be strongly and positively correlated with TMD, including $\mathrm{CMCH}$. Mandibular condyle displacement (CD) resulting from dental arch displacement (DAD) has been shown in contemporary research to be etiologic in the production of common muscle contraction headache $(\mathrm{CMCH})$ and temporo-mandibular dysfunction (TMD).

\section{Acknowledgements}

No outside funding was provided for this research.

I would like to acknowledge Dr. Robert Wassell and his seminal research article entitled "Do occlusal factors play a part in temporomandibular dysfunction?” J Dent June, 1989: Vol 17: 3, 101-110. This is the finest publication that I have ever found on this topic and is the basis for this subsequent paper. I have quoted this paper extensively, while at the same time attempting to add to the knowledge base on this subject of paramount importance to the practice of dentistry and orthodontics.

\section{Publications}

1) Wassell, R.W. (1989) Do Occlusal Factors Play a Part in Temporomandi- 
bular Dysfunction? Journal of Dentistry, 17, 101-110.

https://doi.org/10.1016/0300-5712(89)90100-0

2) Wassell, R.W., Steele, J.G. and Welsh, G. (1998) Consideration When Planning Occlusal Rehabilitation: A Review of the Literature. International Dental Journal, 48, 571-581. https://doi.org/10.1111/j.1875-595X.1998.tb00494.x

3) Wassell, R.W., Adams, N. and Kelly, P.J. (2000) Treatment of Temporomandibular Disorders by Stabilizing Splints in General Dental Practice: 1 Year Results. Journal of Dental Research, 79, 622.

4) Steele, J.G., Nohl, F.S.A. and Wassell, R.W. (2002) Crowns and Other Extra-Coronal Restorations: Occlusa Considerations and Articulaor Selection. British Dental Journal, 192, 377-387. https://doi.org/10.1038/sj.bdj.4801380

5) Wassell, R.W., Adams, N. and Kelly, P.J. (2004) Treatment of Temporomandibular Disorders by Stabilizing Splints in General Dental Practice: Results after Initial Treatment. British Dental Journal, 197, 35-41.

https://doi.org/10.1038/sj.bdj.4811420

6) Wassell, R.W., Adams, N. and Kelly, P.J. (2006) The Treatment of Temporomandibular Disorders with Stabilizing Splints in General Dental Practice: One Year Follow-Up. Journal of the American Dental Association, 137, 1089-1098. https://doi.org/10.14219/jada.archive.2006.0347

7) John, M.T., Reißmann, D., Schierz, O. and Wassell, R.W. (2007) Oral Health-Related Quality of Life in Patients with Temporomandibular Disorders. Journal of Orofacial Pain, 21, 46-54.

8) Reissmann, D.R., John, M.T., Schierz, O. and Wassell, R.W. (2007) Functional and Psychosocial Impact Related to Specific Temporomandibular Disorder Diagnoses. Journal of Dentistry, 35, 643-650.

https://doi.org/10.1016/j.jdent.2007.04.010

9) Durham, J., Moufti, M.A., Exley, C., Meechan, J.G., Wassell, R.W. and Steele, J.G. (2008) Item Selection for a Temporomandibular Disorders (TMD) Specific Outcome Measure. Journal of Dental Research, 87, Abstract No. 0277.

10) Durham, J., Moufti, M.A., Steele, J.G., Wassell, R.W. and Exley, C. (2008) Can We Improve the Management of Patients with Temporomandibular Disorders? Journal of Dental Research, 87, Abstract No. 1915.

11) Wassell, R.W., Naru, A., Steele, J. and Nohl, F. (2008) Applied Occlusion. Quintessence Books, London.

12) Durham, J., Steele, J.G., Wassell, R.W., Exley, C., Meechan, J.G., Allen, P.F. and Moufti, A.M. (2011) Creating a Patient Based Condition-Specific Outcome Measure for Temporomandibular Disorders (TMDs): Oral Health Impact Profile for TMDs (OHIP-TMDs). Journal of Oral Rehabilitation, (epub ahead of print). https://doi.org/10.1111/j.1365-2842.2011.02233.x

\section{Conflict of Interest Statement/Competing Financial Interest Statement}

I declare no conflict of interest or competing financial interests.

I wish to confirm that there are no known conflicts of interest associated with 
this publication and there has been no significant financial support for this work that could have influenced its outcome.

I confirm that the manuscript has been read and approved by the named author and that there are no other persons who satisfied the criteria for authorship but are not listed.

I confirm that I have given due consideration to the protection of intellectual property associated with this work and that there are no impediments to publication, including the timing of publication, with respect to intellectual property.

I understand that the Corresponding Author is the sole contact for the Editorial process (including Editorial Manager and direct communications with the office). I am responsible for communication regarding progress, submissions of revisions, and final approval of proofs.

I confirm that I have provided a current, correct email address which is accessible by the Corresponding Author and which has been configured to accept email from cordrayortho@aol.com.

\section{References}

[1] Wassell, R.W. (1989) Do Occlusal Factors Play a Part in Temporomandibular Dysfunction? Journal of Dentistry, 17, 101-110. https://doi.org/10.1016/0300-5712(89)90100-0

[2] Solberg, W.K. (1986) TM Disorders: Background and the Clinical Problems. British Dental Journal, 160, 157-161. https://doi.org/10.1038/sj.bdj.4805796

[3] Diamond, S. and Baltes, B.J. (1973) The Diagnosis and Treatment of Headache. Chicago Medical School Quarterly, 32, 41.

[4] Costen, J.B. (1934) Syndrome of Ear and Sinus Symptoms, Dependent on Disturbed Function of the TM Joint. Annals of Otology, Rhinology \& Laryngology, 43, 1-15. https://doi.org/10.1177/000348943404300101

[5] Jarabak, J.R. (1956) An Electromyographic Analysis of Muscular and TM Joint Disturbances Due to Imbalances of Occlusion. Angle Orthodontist, 26, 170-190.

[6] Shore, N.A. (1959) Occlusal Equilibration and TM Joint Dysfunction. JB Lippincott, Philadelphia.

[7] Harris, M. and Davies, G. (1980) In: Jones, J.G. and Mason, M.K., Eds., Oral Manisfestations of Systemic Disease, WB Saunders, Philadelphia.

[8] Laskin, D.M. (1969) Etiology of Pain Dysfunction Syndrome. JADA, 79, 147-153. https://doi.org/10.14219/jada.archive.1969.0234

[9] Pullinger, A.G., et al. (1985) Etiological Factors Associated with TM Disorders. Journal of Dental Research, 64, 269.

[10] Ash, M.M. (1986) Current Concepts in the Etiology, Diagnosis, and Treatment of TMJ and Muscle Dysfunction. Journal of Oral Rehabilitation, 13, 1-20. https://doi.org/10.1111/j.1365-2842.1986.tb01551.x

[11] Randow, K., Carlsson, K., et al. (1976) The Effect of an Occlusal Interference on the Masticatory System. Odontologisk Revy, 27, 245-256.

[12] Riise, C. and Skeikholeslam, A. (1982) The Influence of Experimental Interfering Occlusal Contacts on the Postural Activity of the Anterior Temporal and Masseter Muscles in Young Adults. Journal of Oral Rehabilitation, 9, 419-425. https://doi.org/10.1111/j.1365-2842.1982.tb01031.x

[13] Plata, M., Barghi, N. and Rey, R. (1982) Clinical Evaluation of Induced Occlusal 
Disharmonies. Journal of Dental Research, 61, 204.

[14] Rugh, J.D., Barghi, N. and Drago, C.J. (1984) Experimental Occlusal Discrepancies and Nocturnal Bruxism. JPD, 51, 548-553.

https://doi.org/10.1016/0022-3913(84)90312-3

[15] Magnusson, T. and Enbom, L. (1984) Signs and Symptoms of Mandibular Dysfunction after Introduction of Experimental Balancing-Side Interferences. Acta Odontologica Scandinavica, 42, 129-134. https://doi.org/10.3109/00016358408993863

[16] Shiekholeslam, A., Moller, E. and Louis, I. (1982) Postural and Maximal Activity in Elevators of Mandible before and after Treatment of Functional Disorders. Scandinavian Journal of Dental Research, 90, 37-46.

https://doi.org/10.1111/j.1600-0722.1982.tb01522.x

[17] Bessette, R.W. and Shatkin, S.S. (1979) Predicting by EMG the Results of Nonsurgical Treatment of TM Joint Syndrome. Plastic and Reconstructive Surgery, 64, 232238. https://doi.org/10.1097/00006534-197908000-00016

[18] Skiba, T.J. and Laskin, D.M. (1981) Masticatory Muscle Silend Periods in Patients with MPD Syndrome before and after Treatment. Journal of Dental Research, 60, 699-706. https://doi.org/10.1177/00220345810600030501

[19] Cox, P.J., et al. (1982) The Measurement of Masseteric Silent Periods after Experimental Tooth Grinding. Journal of Oral Rehabilitation, 9, 487-492. https://doi.org/10.1111/j.1365-2842.1982.tb01038.x

[20] Sherman, R.A. (1985) Relationship between Jaw Pain and Jaw Muscle Contraction Level: Underlying Factors and Treatment Effectiveness. JPD, 54, 114-118. https://doi.org/10.1016/s0022-3913(85)80084-6

[21] Ramfjord, S.P. (1961) Bruxism, a Clinical and EMG Study. JADA, 62, 21-44. https://doi.org/10.14219/jada.archive.1961.0002

[22] Ramfjord, S.P. (1961) Dysfunctional TM Joint and Muscle Pain. JPD, 11, 353-374.

[23] Kloprogge, M.J. and Van Griethuysen, A.M. (1976) Disturbances in the Contraction and Coordination Pattern of the Masticatory Muscles Due to Dental Restorations. Journal of Oral Rehabilitation, 3, 207-216. https://doi.org/10.1111/j.1365-2842.1976.tb00946.x

[24] Rugh, J.D. and Solberg, W.K. (1985) Oral Health Status in the US: TM Disorders. Journal of Dental Education, 49, 398-405.

[25] Heloe, B. and Heloe, L.A. (1975) Characteristics of a Group of Patients with TM Disorders. Community Dentistry and Oral Epidemiology, 3, 72-79. https://doi.org/10.1111/j.1600-0528.1975.tb00284.x

[26] Ramfjord, S.P. and Ash, M.M. (1983) Occlusion. 3rd Edition, WB Saunders, Philadelphia.

[27] Moody, P.M., et al. (1981) Stress-Pain Relationship in MPD Syndrome Patients and Non-MPD Syndrome Patients. JPD, 45, 84-87. https://doi.org/10.1016/0022-3913(81)90016-0

[28] Moody, P.M., et al. (1982) Recent Life Changes and MPD Syndrome. JPD, 48, 328330.

[29] Franks, A.S.T. (1964) The Social Character of TM Joint Dysfunction. Dental Practice, 15, 94-100.

[30] Ingervall, B. and Hedegard, B. (1974) Subjective Evaluation of Functional Disturbances of the Masticatory System in Young Swedish Men. Community Dentistry and Oral Epidemiology, 2, 149-152. https://doi.org/10.1111/j.1600-0528.1974.tb01672.x

[31] Egermark-Ericksson, I., Ingervall, B. and Carlsson, G. (1983) The Dependence of 
Mandibular Dysfunction in Children on Functional and Morphologic Malocclusion. American Journal of Orthodontics, 83, 187-194. https://doi.org/10.1016/0002-9416(83)90082-9

[32] Berry, D.C. and Singh, B.P. (1984) Effect of EMG Biofeedback Therapy on Occlusal Contacts. JPD, 51, 397-403.

[33] Girardot, R.A. (1987) The Nature of Condylar Displacement in Patients with TM Pain-Dysfunction. Orthodontic Review, 1, 16-23.

[34] Crawford, S.D. (1999) The Relationship between Condylar Axis Position as Determined by the Occlusion and Measured by the CPI Instrument and Signs and Symptoms of TM Joint Dysfunction. Angle Orthodontist, 69, 103-115.

[35] Dawson, P.E. (2007) Functional Occlusion: From TMJ to Smile Design. CV Mosby, St. Louis, 48-50, 76-96, 108, 264-275, 281, 297, 352-354, 408.

[36] Roura, N. and Clayton, J.A. (1975) Pantographic Records of TMJ Dysfunction Subjects Treated with Occlusal Splints. JPD, 33, 442-453.

[37] Pameijer, J.H.N. (1985) Periodontal and Occlusal Factors in Crown and Bridge Procedures. Dental Centre for Post Graduate Courses, Amsterdam.

[38] Campbell, J. (1958) Distribution and Treatment of Pain in TM Arthroses. British Dental Journal, 105, 393-407.

[39] Watt, D.M. (1981) Gnathosonic Diagnosis and Occlusal Dynamics. Praeger, Holt, Saunders, Eastbourne.

[40] Greene, C.S. and Laskin, D.M. (1972) Splint Therapy for the MPD Syndrome: A Comparative Study. JADA, 84, 624-628.

https://doi.org/10.14219/jada.archive.1972.0090

[41] Foodman, P., Greene, C.S. and Laskin, D.M. (1976) Response of Patients with MPD Syndrome to Mock Occlusal Equilibration. JADA, 92, 755-758. https://doi.org/10.14219/jada.archive.1976.0419

[42] Helkimo, M. (1974) Studies on Function and Dysfunction of the Masticatory System. II Index for Anamnestic and Clinical Dysfunction and Occlusal State. Svensk Tandlakare-Tidskrift, 67, 101-119.

[43] Shields, J.M., Clayton, J.A. and Sindledecker, L.D. (1978) Using Pantographic Tracings to Detect TMJ and Muscle Dysfunction. JPD, 39, 80-87.

[44] Lederman, K.H. and Clayton, J.A. (1982) Patients with Restored Occlusions. Part I: TMJ Dysfunction Determined Be a Pantographic Reproducibility Index. JPD, 47, 198-205. https://doi.org/10.1016/0022-3913(82)90188-3

[45] Clayton, J.A. (1976) A Pantographic Reproducibility Index (PRI) for Detection of TMJ Dysfunction. Journal of Dental Research, 55, 161 (Abstract).

[46] Crispin, B.J., Myers, G.E. and Clayton, J.A. (1978) Effect of Occlusal Therapy on Pantographic Reproducibility of Mandibular Border Movements. JPD, 40, 29-34. https://doi.org/10.1016/0022-3913(78)90154-3

[47] Mongini, F. (1980) Condylar Remodeling after Occlusal Therapy. JPD, 43, 568-577. https://doi.org/10.1016/0022-3913(80)90333-9

[48] Beard, C.C. and Clayton, J.A. (1980) Effects of Occlusal Splint Therapy on TMJ Dysfunction. JPD, 44, 324-335. https://doi.org/10.1016/0022-3913(80)90021-9

[49] Magnusson, T. and Carlsson, G.E. (1983) Occlusal Adjustment in Patients with Residual or Recurrent of Mandibular Dysfunction. JPD, 49, 706-710.

[50] Solberg, W.K., Clark, G.T. and Rugh, J.D. (1975) Nocturnal EMG Evaluation of Bruxism Patients Undergoing Short Term Splint Therapy. Journal of Oral Rehabilitation, 2, 215-223. https://doi.org/10.1111/j.1365-2842.1975.tb00915.x 
[51] Williamson, E.H. and Lundquist, D.O. (1983) Anterior Guidance: Its Effect on EMG Activity of the Temporal and Masseter Muscles. JPD, 49, 816-823.

[52] Clark, G.T. (1984) A Critical Evaluation of Orthopedic Interocclusal Appliance Therapy: Design, Theory, and Overall Effectiveness. JADA, 108, 359-364. https://doi.org/10.14219/jada.archive.1984.0010

[53] Clark, G.T. (1984) A Critical Evaluation of Orthopedic Appliance Therapy: Effectiveness for Specific Symptoms. JADA, 108, 364-368. https://doi.org/10.14219/jada.archive.1984.0002

[54] Wahlund, K. and List, T. (2003) Treatment of TM Disorders among Adolescents: A Comparison between Occlusal Appliance, Relaxation Training, and Brief Information. Acta Odontologica Scandinavica, 61, 203-211. https://doi.org/10.1080/00016350310003891

[55] Maloney, F. and Howard, J.A. (1986) Internal Derangements of the TM Joint. III. Anterior Repositioning Splint Therapy. Australian Dental Journal, 31, 30-39. https://doi.org/10.1111/j.1834-7819.1986.tb02980.x

[56] Howat, A.P., Capp, N.J. and Barrett, N.V.J. (1991) A Color Atlas of Occlusion and Malocclusion. CV Mosby, St. Louis.

[57] Okeson, J.P. (1993) Management of TM Disorders and Occlusion. 3rd Edition, Vol. 113, CV Mosby, St. Louis, 453-458.

[58] Dawson, P.E. (1996) A Classification System for Occlusions That Relates Maximal Intercuspation to the Position and Condition of the TM Joints. JPD, 75, 60-68.

[59] Sicher, H. (1980) Sicher's Oral Anatomy. 7th Edition, CV Mosby, St. Louis, 178.

[60] Hylander, W.L. (1979) Functional Anatomy. In: Sarnat, B.G. and Laskin, D.M., Eds., The Temporomandibular Joint, 3rd Edition, Thomas, Springfield.

[61] Lundeen, H.C. and Gibbs, C.H. (1982) Advances in Occlusion. Postgraduate Dental Handbook, Vol. 14, John Wright Publisher, University of Florida, Gainesville, Florida, 7-10.

[62] Huffman, R.W. and Regenos, J.W. (1978) Principles of Occlusion. Hand R Press, Columbus.

[63] Wood, D.P. and Elliot, R.W. (1994) Reproducibility of the Centric Relation Wax Bite Technic. Angle Orthodontist, 64, 211-221.

[64] Slavicek, R.J. (1988) Clinical and Instrumental Functional Analysis for Diagnosis and Treatment Planning, Part IV: Instrumental Analysis of Mandibular Casts Using the Mandibular Position Indicator. Journal of Clinical Orthodontics, 22, 566-575.

[65] Stuart, C.E. (1964) Good Occlusion for Natural Teeth. JPD, 14, 716-724. https://doi.org/10.1016/0022-3913(64)90207-0

[66] Pousselt, V. (1968) Physiology of Occlusion and Rehabilitation. 2nd Edition, Blackwell Scientific Publications, Oxford.

[67] Ackerman, J. and Proffit, W. (1997) Soft Tissue Limitations in Orthodontics: Treatment Planning Guidelines. Angle Orthodontist, 67, 327.

[68] Roth, R.H. (1976) The Maintenance System and Occlusal Dynamics. Dental Clinics of North America, 20, 761-788.

[69] Calagna, L.S., Silverman, S.I. and Garfinkel, L. (1973) Influence of Neuromuscular Conditioning on Centric Registrations. JPD, 30, 598.

[70] Capp, N.J. and Clayton, J.A. (1985) A Technic for Evaluation of Centric Relation Tooth Contacts: Part II: Following Use of an Occlusal Splint for Treatment of TMJ Dysfunction. JPD, 54, 697-705.

[71] Koveleski, W.C. and DeBoever, J. (1975) Influence of Occlusal Splints on Jaw Posi- 
tion and Musculature in Patients with TMJ Dysfunction. JPD, 33, 321-327.

[72] Teo, C.S. and Wise, M.D. (1981) Comparison of Retruded Axis Articular Mountings with and without Applied Muscular Force. Journal of Oral Rehabilitation, 8, 363-376. https://doi.org/10.1111/j.1365-2842.1981.tb00510.x

[73] Hoffman, P.J., Silverman, S.I. and Garfinkel, L. (1973) Comparison of Condylar Position in Centric Relation and in Centric Occlusion in Dentulous Patients. JPD, 30, 582-588.

[74] Rosner, D. (1982) Hinge Axis Translation from Retruded Contact Position to Intercuspal Position in Dentulous Subjects in Treatment. JPD, 48, 713-718.

[75] Alexander, S.R., Moore, R.N. and Dubois, L.M. (1993) Mandibular Condyle Position: Comparison of Articulator Mountings and Magnetic Resonance Imaging. American Journal of Orthodontics, 104, 230-239. https://doi.org/10.1016/S0889-5406(05)81724-X

[76] Utt, T.W., Meyers, C.E., Wierzba, T.F. and Hondrum, S.O. (1995) A Three-Dimensional Comparison of Condylar Position Changes between Centric Relation and Centric Occlusion Using the Mandibular Position Indicator. American Journal of Orthodontics, 107, 298-308. https://doi.org/10.1016/S0889-5406(95)70146-X

[77] Esmay, T.R. (1995) The Relationship of Condylar Position Changes between Centric Relation and Maximum Intercuspation in Orthodontic Treated and Non-Orthodontic Treated Individuals. Master's Thesis, NYU, NYC.

[78] Hidaka, O., Adachi, S. and Takada, K. (2002) The Difference in Condylar Position between Centric Relation and Centric Occlusion in Pretreatment Japanese Orthodontic Patients. Angle Orthodontist, 72, 295-301.

[79] Williamson, E.H., Evans, D.L., Barton, W.A and Williams, B.H. (1977) The Effect of Biteplane Use on Terminal Hinge Axis Location. Angle Orthodontist, 47, 25-33.

[80] Williamson, E.H., Steinke, R.M., Morse, P.K. and Swift, T.R. ((1980) Centric Relation: A Comparison of Muscle-Determined Position and Operator Guidance. American Journal of Orthodontics, 77, 133-145. https://doi.org/10.1016/0002-9416(80)90002-0

[81] Williamson, E.H. (1978) Laminagraphic Study of Mandibular Condyle Position When Recording Centric Relation. JPD, 39, 561-564. https://doi.org/10.1016/s0022-3913(78)80194-2

[82] Girardot, R.A. (2001) Comparison of Condylar Position in Hyperdivergent and Hypodivergent Facial Skeletal Types. Angle Orthodontist, 71, 240-246.

[83] Wood, D.P., Floreani, K.J., Galil, K.A. and Teteruk, W.R. (1994) The Effect of Incisal Bite Force on Condylar Seating. Angle Orthodontist, 64, 53-61.

[84] Karl, P.J. and Foley, T.F. (1999) The Use of a Deprogramming Appliance to Obtain Centric Relation Records. Angle Orthodontist, 69, 117-125.

[85] Dawson, P.E. (1989) Evaluation, Diagnosis, and Treatment of Occlusal Problems. 2nd Edition, CV Mosby, St. Louis, 28-33, 41-45, 132, 590-591.

[86] Lundeen, H. (1972) Centric Relation Records-The Effects of Muscle Action. JPD, 31, 244-251.

[87] Lucia, V.O. (1983) Modern Gnathological Concepts-Updated. Quintessence Publishing, Chicago, 39-53.

[88] Throckmorton, G.S., Groshan, G.J. and Boyd, S.B. (1990) Muscle Activity Patterns and Control of TMJ Loads. JPD, 63, 685-695.

[89] Lucia, V.O. (1964) A Technique for Recording Centric Relation. JPD, 14, 492-505. https://doi.org/10.1016/s0022-3913(64)80017-2 
[90] Long, J.H. (1973) Locating Centric Relation with a Leaf Gauge. JPD, 29, 608-610. https://doi.org/10.1016/0022-3913(73)90267-9

[91] Kantor, M.E., Silverman, S.I. and Garfinkel, L. (1972) Centric Relation Recording Techniques: Comparative Investigation. JPD, 28, 593-600. https://doi.org/10.1016/0022-3913(72)90107-2

[92] Fenlon, M.R. and Woeffel, J.B. (1993) Condylar Position Recorded Using Leaf Gauges and Specific Closure Forces. International Journal of Prosthodontics, 6, 402408.

[93] Johnston, L.E. and Huffman, R.W. (1988) Gnathologic Assessment of Centric Slides in Post-Retention Orthodontic Patients. JPD, 60, 712-715.

[94] American Dental Association. Recommendations in Radiographic Practices (1984) Council on Dental Materials, Instruments, and Equipment. JADA, 109, 764-765.

[95] American Academy of Craniomandibular Disorders (1990) Craniomandibular Disorders: Evaluation, Diagnosis, and Management. Quintessence, Chicago, 25-33.

[96] Blaschke, D.D. and Blaschke, T.J. (1981) Normal TMJ Bony Relationships in Centric Occlusions. Journal of Dental Research, 60, 98-104. https://doi.org/10.1177/00220345810600021901

[97] Katzberg, R.W., Keith, D.A., Ten Eik, W.R. and Guralnik, W.C. (1983) Internal Derangements of the TM Joint: An Assessment of Condylar Position in Centric Occlusion. JPD, 49, 250.

[98] Dixon, D.C., Graham, G.S. and Mayhew, R.B. (1984) The Validity of Transcranial Radiology in Diagnosing TMJ Anterior Disc Displacement. JADA, 108, 615. https://doi.org/10.14219/jada.archive.1984.0399

[99] Aquilino, S.A., Matteson, S.R., Holland, G.A. and Phillips, C. (1985) Evaluation of Condylar Position from TM Joint Radiography. JPD, 53, 88.

[100] Pullinger, A.G., Hollender, L., Solberg, W.K. and Petersson, A. (1985) A Tomographic Study of Mandibular Condyle Position in an Asymptomatic Population. $J P D, 53,706-712$.

[101] Pullinger, A.G., Solberg, W.K., Hollender, L. and Guichet, D. (1986) Tomographic Condyle Position in Diagnostic Subgroups of TMD. JPD, 55, 723-729.

[102] Bean, L.R. and Thomas, C.A. (1987) Significance of Condylar Positions in Patients with TM Disorders. JADA, 114, 76. https://doi.org/10.14219/jada.archive.1987.0043

[103] Ronquilo, H.I., Gray, J. and Tallants, R.H. (1988) Tomographic Analysis of Mandibular Condyle Position as Compared to Arthrographic Findings of the TM Joint. Journal of Craniomandibular Disorders, 2, 59.

[104] Brand, J.W., Whinery, J.G. and Anderson, Q.N. (1989) Condylar Position as a Predictor of TM Joint Internal Derangements. Oral Surgery, Oral Medicine, Oral Pathology, Oral Radiology, and Endodontology, 67, 469. https://doi.org/10.1016/0030-4220(89)90394-0

[105] Dixon, D.C. (1991) Diagnostic Imaging of the TM Joint. Dental Clinics of North America, 35, 53.

[106] Leidberg, J., Rohlin, M. and Westesson, P.L. (1985) Observer Performance in Assessment of Condylar Position in TM Joint Radiographs. Acta Odontologica Scandinavica, 43, 53. https://doi.org/10.3109/00016358509064140

[107] Laskin, D., Greenfield, W. and Gale, E. (1983) The President's Conference on the Examination, Diagnosis, and Management of TM Disorders (June 1-4, 1982). Chicago ADA.

[108] Griffiths, R.H. (1983) Report of the President's Conference on the Examination, 
Diagnosis, and Management of TM Disorders. JADA, 106, 75. https://doi.org/10.14219/jada.archive.1983.0020

[109] McNeil, D., Mohl, N.D., Rugh, J.D. and Tanaka, T.T. (1990) TM Disorders: Diagnosis, Management, Education and Research. JADA, 120, 253. https://doi.org/10.14219/jada.archive.1990.0049

[110] Laskin, D.M. and Greene, C.S. (1990) Diagnostic Methods for TM Disorders: What Have We Learned in Two Decades? Anesthesia Progress, 37, 66.

[111] Mohl, N.D. (1993) Reliability and Validity of Diagnostic Modalities for TM Disorders. Advances in Dental Research, 7, 113.

[112] Pullinger, A.G. and Hollender, L. (1986) Variation in Condyle-Fossa Relationships According to Different Methods of Evaulation in Tomograms. Oral Surgery, Oral Medicine, Oral Pathology, Oral Radiology, and Endodontology, 62, 710-727.

[113] Hatcher, D.C., Blom, R.J. and Baker, C.G. (1986) TM Joint Spatial Relationships: Osseous and Soft Tissues. JPD, 56, 344-353.

[114] Shildkraut, M., Wood, D.P. and Hunter, W.S. (1994) The CR-CO Discrepancy and Its Effect on Cephalometric Measurements. Angle Orthodontist, 64, 333-342.

[115] Wood, D.P. and Korne, P.H. (1992) Estimated and True Hinge Axis: A Comparison of Condylar Displacements. Angle Orthodontist, 62, 167-175.

[116] Hicks, S.T. and Wood, D.P. (1996) Recording Condylar Movement with Two Facebow Systems. Angle Orthodontist, 66, 293-300.

[117] Rosner, D. and Goldberg, G.F. (1986) Condylar Retruded Contact Position and Intercuspal Position and Correlation in Dentulous Patients. Part 1: Three Dimensional Analysis of Condylar Registrations. JPD, 56, 230.

[118] Greene, C.S. (1988) Orthodontics and TM Disorders. Dental Clinics of North America, 32, 529-538.

[119] Just, J.K., Perry, H.T. and Greene, C.S. (1991) Treating TM Disorders: A Survey on Diagnosis, Etiology, and Management. JADA, 122, 55-60.

https://doi.org/10.14219/jada.archive.1991.0265

[120] Mohl, N.D. (1991) TM Disorders: The Role of Occlusion, TMJ Imaging, and Electronic Devices. Journal of the American College of Dentists, 58, 4-9.

[121] Pullinger, A. and Hollender, L. (1985) Assessment of Mandibular Condyle Position: A Comparison of Transcranial Radiographs and Linear Tomograms. Oral Surgery, Oral Medicine, Oral Pathology, Oral Radiology, and Endodontology, 60, 329-334. https://doi.org/10.1016/0030-4220(85)90319-6

[122] Seligman, D.A. and Pullinger, A.G. (1991) The Role of Interculpal Occlusal Relationships in TM Disorders: A Review. Journal of Craniomandibular Disorders, 5, 96-106.

[123] Pullinger, A.G. and Seligman, D.A. (1987) TMJ Osteoarthrosis: Differentiation of Diagnostic Subgroups by Symptom History and Demographics. Journal of Craniomandibular Disorders, 1, 251-256.

[124] Pullinger, A.G., Seligman, D.A. and Solberg, W.K. (1988) TM Disorders Part I: Functional Status, Dentomorphic Features, and Sex Differences in a Non-Patient Population. JPD, 59, 228-235.

[125] Pullinger, A.G., Seligman, D.A. and Solberg, W.K. (1988) TM Disorders Part II: Occlusal Factors Associated with TM Joint Tenderness and Dysfunction. JPD, 59, 363367.

[126] Sadowsky, C. and Begole, E.A. (1980) Long-Term Status of TM Joint Function and Functional Occlusion after Orthodontic Treatment. AJO-DO, 78, 201-212. 
[127] Sadowsky, C. and Polson, A.M. (1984) TM Disorders and Functional Occlusion after Orthodontic Treatment: Results of Two Long-Term Studies. AJO-DO, 86, 386390.

[128] Seligman, D.A. and Pullinger, A.G. (1989) Association of Occlusal Variables among Refined TM Patient Diagnostic Groups. Journal of Craniomandibular Disorders, 3, 227-235.

[129] Seligman, D.A., Pullinger, A.G. and Solberg, W.K. (1988) TM Disorders. Part III: Occlusal and Articular Factors Associated with Muscle Tenderness. JPD, 59, 483489.

[130] Belser, U.C. and Hannam, A.G. (1985) The Influence of Altered Working-Side Occlusal Guidance on Masticatory Muscles and Related Jaw Movement. JPD, 53, 406413.

[131] Christenson, L.V. and Ziebert, G.J. (1986) Effects of Experimental Loss of Teeth on the TM Joint. Journal of Oral Rehabilitation, 13, 587-598. https://doi.org/10.1111/j.1365-2842.1986.tb00682.x

[132] DeLaat, A., van Steenberghe, D. and Lasaffre, E. (1986) Occlusal Relationships and TM Joint Dysfunction. Part II: Correlations between Occlusal and Articular Parameters and Symptoms of TMJ Dysfunction by Means of Stepwise Logistic Regression. JPD, 55, 116-120.

[133] Mongini, F. (1977) Anatomic and Clinical Evaluation of the Relationship between the TM Joint and Occlusion. JPD, 38, 539-551.

[134] Mongini, F. and Schmid, W. (1982) Assessment of the Therapeutic Position for Orthodontic Diagnosis and Treatment. AJO-DO, 82, 513-518.

[135] Nilner, M. (1983) Relationships between Oral Parafunctions and Functional Disturbances in the Stomatognathic System among 15 to 18 Year Olds. Acta Odontologica Scandinavica, 41, 197-201. https://doi.org/10.3109/00016358309162324

[136] Okeson, J. (1981) Etiology and Treatment of Occlusal Pathosis and Associated Facial Pain. JPD, 45, 199-204. https://doi.org/10.1016/0022-3913(81)90340-1

[137] Rugh, J. and Harlan, J. (1988) Nocturnal Bruxism and TM Disorders. Advances in Neurology, 49, 329-341.

[138] Kirveskari, P., Alanen, P. and Jamsa, T. (1992) Association between craniomandibular disorders and occlusal interferences in children. JPD, 67, 692-696.

[139] Gibbs, C. and Lundeen, H. (2005) The Function of Teeth. L and G Publishers LLC, Gainesville, Florida.

[140] Geering, A.H. (1974) Occlusal Interferences and Functional Disturbances of the Masticatory System. Journal of Clinical Periodontology, 1, 112-119. https://doi.org/10.1111/j.1600-051X.1974.tb01246.x

[141] Weinberg, L. (1979) Role of Condylar Position in TMD-Pain Syndrome. JPD, 41, 636-643.

[142] Williams, B.H. (1983) Oriented Lateral TM Joint Laminagraphs. Angle Orthodontist, 53, 228-233.

[143] Dumas, A., Moaddab, M.B. and Willis, H.B. (1984) A Tomographic Study of the Condyle-Fossa Relationship in Patients with TMD. Journal of Craniomandibular Practice, 2, 316. https://doi.org/10.1080/07345410.1984.11677875

[144] Rosner, D. and Goldberg, G.F. (1986) Condylar Retruded Contact Position and Intercuspal Position in Dentulous Patients. Part II: Patients Classified Be Anamnestic Questionnaire. JPD, 56, 359.

[145] Brand, J.W. and Whinery, J.G. (1989) Condylar Position as a Predictor of TM Joint 
Internal Derangement. Oral Surgery, Oral Medicine, Oral Pathology, Oral Radiology, and Endodontology, 67, 469. https://doi.org/10.1016/0030-4220(89)90394-0

[146] Mohlin, C., Carlsson, G. and Friling, B. (1976) Frequency of Symptoms of Mandibular Dysfunction in Young Swedish Men. Journal of Oral Rehabilitation, 3, 9. https://doi.org/10.1111/j.1365-2842.1976.tb00925.x

[147] Kobayashi, Y. and Hansson, T.L. (1988) Auswirking der okklusion auf den menschlichen poerper. Phillip Journal, 5, 255.

[148] Takeda, Y., Ishihora, H. and Kobayashi, Y. (1989) Influence of Occlusal Interference on Nocturnal Sleep and Masseter Muscle Activity. Journal of Dental Research, 68, Abstract \#561.

[149] Franks, A.S. (1967) The Dental Health of Patients Presenting with TM Joint Dysfunction. British Journal of Oral Surgery, 5, 157. https://doi.org/10.1016/S0007-117X(67)80041-6

[150] Mohlin, B. and Kopps, S. (1978) A Clinical Study on the Relationship between Malocclusions, Occlusal Interferences, and Mandibular Pain and Dysfunction. Swedish Dental Journal, 2, 105-112.

[151] Solberg, W.K., Woo, M.W. and Houston, J.B. (1979) Prevalence of Mandibular Dysfunction in Young Adults. JADA, 98, 25-33. https://doi.org/10.14219/jada.archive.1979.0008

[152] Suzuki, J.B. (1979) Etiology of Parafunction: A Brief Review of Psychology and Occlusal Genesis. Journal of the Western Society of Periodontology Periodontal Abstracts, 27, 48.

[153] Colquitt, T. (1987) The Sleep-Wear Syndrome. JPD, 57, 33. https://doi.org/10.1016/0022-3913(87)90113-2

[154] Ramfjord, S.P. (1961) Dysfunctional TM Joint and Muscle Pain. JPD, 11, 353.

[155] Funakoshi, M., Fugita, N. and Takehana, S. (1976) Relation between Occlusal Interferences and Jaw Muscle Activity in Response to Changes in Head Position. Journal of Dental Research, 55, 648. https://doi.org/10.1177/00220345760550042401

[156] Solberg, W.K. and Seligman, D.A. (1995) TM Orthopedics: A New Vista in Orthodontics. In: Johnston, S.E., Ed., New Vistas in Orthodontics, Lea and Febiger, Philadelphia.

[157] McNamara, D.C. (1978) The Clinical Significance of Median Occlusal Position. Journal of Oral Rehabilitation, 5, 173. https://doi.org/10.1111/j.1365-2842.1978.tb01211.x

[158] Reider, L.E. (1976) The Prevalence and Magnitude of the Mandibular Displacement in a Survey Population. JPD, 35, 299.

[159] Hannam, A.D., et al. (1977) The Relationship between Dental Occlusion, Muscle Activity, and Associated Jaw Movement in Man. Archives of Oral Biology, 22, 2532. https://doi.org/10.1016/0003-9969(77)90135-2

[160] Bush, F.M. (1984) Malocclusion, Mastictory Muscle and TM Joint Tenderness. Journal of Dental Research, 64, 129-133. https://doi.org/10.1177/00220345850640020701

[161] Graham, M.M., Buxham, J. and Stahling, L.M. (1982) A Study of Occlusal Relationships and the Incidence of Myofascial Pain. JPD, 47, 549-555.

[162] Droukas, B., Lindee, C. and Carlsson, G.E. (1984) Relationship between Occlusal Factors and Signs and Symptoms of Mandibular Dysfunction. Acta Odontologica Scandinavica, 42, 277-283. https://doi.org/10.3109/00016358408993881

[163] Droukas, B., Lindee, C. and Carlsson, G.E. (1985) Occlusion and Mandibular Dys- 
function: A Clinical Study of Patients Referred for Functional Disturbances of the Masticatory System. JPD, 53, 402-406.

[164] Solberg, W.K., Flint, R.T. and Brantner, J.P. (1972) TM Joint Pain and Dysfunction: A Clinical Study of Emotional and Occlusal Components. JPD, 28, 412-422.

[165] Roth, R.H. (1995) Point-Counterpoint. AJO-DO, 107, 315-317. https://doi.org/10.1016/s0889-5406(95)90000-4

[166] Wahlund, K., List, T., et al. (2003) Treatment of TM Disorders among Adolescents: A Comparison between Occlusal Appliance, Relaxation Training, and Brief Information. Acta Odontologica Scandinavica, 61, 203-211. https://doi.org/10.1080/00016350310003891

[167] Long, J.H. (1970) Location of the Terminal Hinge Axis by Intraoral Means. JPD, 23, 11-24.

[168] Reider, C.E. (1978) The Frequency of Parafunctional Habits Compared with the Incidence of Mandibular Displacements. JPD, 40, 75.

[169] Solberg, W.K., Woo, M.W. and Houston, J.B. (1979) Prevalence of Mandibular Dysfunction in Young Adults. JADA, 98, 25. https://doi.org/10.14219/jada.archive.1979.0008

[170] Murayama, T., Miauchi, S. and Umekoji, E. (1982) Analysis of the Mandibular Relationship of TMJ-Dysfunction Patients Using the Mandibular Kinesiograph. Journal of Oral Rehabilitation, 9, 217. https://doi.org/10.1111/j.1365-2842.1982.tb01011.x

[171] Mcnamara, J.A., Seligman, D.A. and Okeson, J.P. (1995) Occlusion, Orthodontic Treatment, and TM Disorders: A Review. [Review]. Journal of Orofacial Pain, 9, 73-90.

[172] Lindauer, S.J., Sabol, G., Isaacson, R.J. and Davidovitch, M. (1995) Condylar Movement and Mandibular Rotation during Jaw Opening. AJO-DO, 107, 573-577.

[173] Braun, S., Marcotte, M.R., Freudenthaler, J.W. and Honigle, K. (1997) An Evaluation of Condyle Position in Centric Relation Obtained by Manipulation of the Mandible with and without Leaf Guage Deprogramming. AJO-DO, 111, 34-37.

[174] Ingervall, B. (1972) Tooth Contacts on the Functional and Non-Functional Side in Children and Young Adults. Archives of Oral Biology, 17, 91. https://doi.org/10.1016/0003-9969(72)90147-1

[175] Agerberg, G. and Sandstrom, R. (1988) Frequency of Occlusal Interferences: A Clinical Study in Teenagers and Young Adults. JPD, 59, 212. https://doi.org/10.1016/0022-3913(88)90017-0

[176] deLaat, A. and Van Steenberghe, D. (1985) Occlusal Relationships and TM Joint Dysfunction Part I: Epidemiological Findings. JPD, 54, 835.

[177] Egermark, I., Magnusson, T. and Carlsson, G.E. (1987) A Long Term Epidemiologic Study of the Relationship between Occlusal Factors and Mandibular Dysfunction in Children and Adolescents. Journal of Dental Research, 66, 67-71. https://doi.org/10.1177/00220345870660011501

[178] Greco, P.M. and Vanarsdall, R.L. (1999) An Evaluation of Anterior Temporalis and Masseter Muscle Activity in Appliance Therapy. Angle Orthodontist, 69, 141-146.

[179] Okeson, J.P., Kemper, J.T. and Moody, P.M. (1982) A Study of the Use of Occlusal Splints in the Treatment of Acute and Chronic Patients with Craniomandibular Disorders. JPD, 48, 708.

[180] Kemper, J.T. and Okeson, J.P. (1983) Craniomandibular Disorders and Headaches. JPD, 49, 702-705. https://doi.org/10.1016/0022-3913(83)90400-6 
[181] Wahlund, K. and List, T. (2002) Treatment of TM Disorders. A Comparison between Occlusal Appliances. Acta Odontologica Scandinavica, 60, 248-254.

[182] Sears, V.H. (1952) Mandibular Condyle Migration as Influenced by Tooth Occlusion. JADA, 45, 179-192. https://doi.org/10.14219/jada.archive.1952.0179

[183] Long, J.H. (1970) Location of Terminal Hinge Axis by Intra-Oral Means. JPD, 23, 11-24.

[184] Shafagh, I., Yoder, J.L. and Thayer, K.E. (1975) Diurinal Variance of Centric Relation Position. JPD, 34, 574.

[185] Shafagh, I. and Amirloo, R. (1979) Replicability of Chin-Point Guidance and Anterior Deprogrammer for Recording Centric Relation. JPD, 42, 402-404.

[186] Hodge Jr., L.C. and Mahan, P.E. (1967) A Study of Posterior Mandibular Movement from Intercuspal Occlusal Position. Journal of Dental Research, 40, 419.

[187] Roth, R.H. (1973) TM Pain-Dysfunction and Occlusal Relationships. Angle Orthodontist, 43, 136.

[188] Shore, N.A. (1976) TM Joint Dysfunction and Occlusal Equilibration. 2nd Edition, JB Lippincott Co, Philadelphia, 138, 143.

[189] Thilander, B., Guillermo, R., Pena, L. and Mayorga, C. (2002) Prevalence of TM Dysfunction and Its Association with Malocclusion in Children and Adolescents: An Epidemiologic Study Related to Specified Stages of Dental Development. Angle Orthodontist, 72, 146-154.

[190] Egermark, I., Magnusson, T. and Carlsson, G.E. (2003) A 20-Year Followup of Signs and Symptoms of TM Disorders and Malocclusions in Subjects with and without Orthodontic Treatment in Childhood. Angle Orthodontist, 73, 109-114.

[191] Mohlin, B., Derweduwen, K., Pilley, R., et al. (2004) Malocclusion and Temporomandibular Disorder: A Comparison of Adolescents with Moderate to Severe Dysfunction with Those without Signs and Symptoms of Temporomandibular Disorder and Their Further Development to 30 Years of Age. Angle Orthodontist, 74, 319 327.

[192] Lindblom, G.T. (1976) TM Joint Function. In: Anderson, D.J. and Matthews, B., Eds., Mastication, John Wright and Sons Ltd., Bristol.

[193] Mongini, F. (1982) Combined Method to Determine the Therapeutic Position for Occlusal Rehabilitation. JPD, 47, 434. https://doi.org/10.1016/s0022-3913(82)80097-8

[194] Mongini, F. (1981) The Importance of Radiography in the Diagnosis of TM Dysfunction. JPD, 45, 186-198.

[195] Krueger, D.M. and Dale, B.G. (1982) Analysis and Correction of Condylar Displacement of the TMJ. JPD, 47, 646-653.

[196] Weinberg, L.A. (1983) The Role of Stress, Occlusion, and Condylar Position in TM Joint Dysfunction-Pain. JPD, 49, 532-545.

[197] Cacchiotti, D.A., Bianchi, P., McNeill, C. and Plesh, O. (1989) Use of the Mandibular Position Indicator in TMJ Disorder Diagnosis. Journal of Dental Research, 68, 391.

[198] Proffit, W.R. (1986) Contemporary Orthodontics. CV Mosby, St. Louis, 134.

[199] Hansson, T. (1982) Presentation to the Foundation for Orthodontic Research. Hilton Head Island, SC.

[200] Cordray, F.E. (2006) Three Dimensional Analysis of Models Articulatd in the Seated Condylar Position from a Deprogrammed Asymptomatic Population: A Prospective Study. Part I. AJO-DO, 129, 619-630. 
[201] Cordray, F.E. (2016) Articulated Dental Cast Analysis of Asymptomatic and Symptomatic Populations. IJOS, 8, 126-132. https://doi.org/10.1038/ijos.2015.44

[202] Weffort, S.Y.K. and Fantini, S.M. (2010) Condylar Displacement between Centric Relation and Maximum Intercuspation in Symptomatic and Asymptomatic Individuals. Angle Orthodontist, 80, 835-842. https://doi.org/10.2319/090909-510.1

[203] He, S.S., Deng, X., Wamalwa, P. and Chen, S. (2010) Correlation between Centric Relation-Maximum Intercuspation Discrepancy and Temporomandibular Joint Dysfunction. Acta Odontologica Scandinavica, 68, 368-376. https://doi.org/10.3109/00016357.2010.517552

[204] Padala, S., Padmanabhan, S. and Chithranjan, A.B. (2012) Comparative Evaluation of Condylar Position in Symptomatic (TMJ Dysfunction) and Asymptomatic Individuals. Indian Journal of Dental Research, 23, 122-127.

https://doi.org/10.4103/0970-9290.99060

Submit or recommend next manuscript to SCIRP and we will provide best service for you:

Accepting pre-submission inquiries through Email, Facebook, LinkedIn, Twitter, etc. A wide selection of journals (inclusive of 9 subjects, more than 200 journals)

Providing 24-hour high-quality service

User-friendly online submission system

Fair and swift peer-review system

Efficient typesetting and proofreading procedure

Display of the result of downloads and visits, as well as the number of cited articles

Maximum dissemination of your research work

Submit your manuscript at: http://papersubmission.scirp.org/

Or contact ojst@scirp.org 